\title{
Octopaminergic neurons have multiple targets in Drosophila larval mushroom body calyx and can modulate behavioral odor discrimination
}

\author{
J.Y. Hilary Wong, ${ }^{1}$ Bo Angela Wan, ${ }^{1}$ Tom Bland, Marcella Montagnese, \\ Alex D. McLachlan, Cahir J. O'Kane, Shuo Wei Zhang, and Liria M. Masuda-Nakagawa \\ Department of Genetics, University of Cambridge, Cambridge CB2 3EH, United Kingdom
}

\begin{abstract}
Discrimination of sensory signals is essential for an organism to form and retrieve memories of relevance in a given behavioral context. Sensory representations are modified dynamically by changes in behavioral state, facilitating context-dependent selection of behavior, through signals carried by noradrenergic input in mammals, or octopamine (OA) in insects. To understand the circuit mechanisms of this signaling, we characterized the function of two OA neurons, sVUMl neurons, that originate in the subesophageal zone (SEZ) and target the input region of the memory center, the mushroom body (MB) calyx, in larval Drosophila. We found that sVUMl neurons target multiple neurons, including olfactory projection neurons (PNs), the inhibitory neuron APL, and a pair of extrinsic output neurons, but relatively few mushroom body intrinsic neurons, Kenyon cells. PN terminals carried the OA receptor Oamb, a Drosophila $\alpha 1$-adrenergic receptor ortholog. Using an odor discrimination learning paradigm, we showed that optogenetic activation of OA neurons compromised discrimination of similar odors but not learning ability. Our results suggest that sVUMl neurons modify odor representations via multiple extrinsic inputs at the sensory input area to the $\mathrm{MB}$ olfactory learning circuit.
\end{abstract}

[Supplemental material is available for this article.]

Behavioral choices depend on discrimination among "sensory objects," which are neural representations of multiple coincident sensory inputs, across a range of sensory modalities. For example, "odor objects" (Gottfried 2009; Wilson and Sullivan 2011; Gire et al. 2013) are represented in sparse ensembles of neurons, that are coincidence detectors of multiple parallel inputs from odor quality channels. This principle is used widely in animals, including in mushroom bodies (MBs), the insect center for associative memory (Masuda-Nakagawa et al. 2005; Honegger et al. 2011), and in the piriform cortex (PCX) of mammals (Stettler and Axel 2009; Davison and Ehlers 2011).

The selectivity of sensory representations can be modulated dynamically by changes in behavioral state, allowing an animal to learn and respond according to perceptual task. In mammals, the noradrenergic system originating in the locus coeruleus (LC) is implicated in signaling behavioral states such as attention, arousal and expectation (Aston-Jones and Cohen 2005; Sara and Bouret 2012).

In insects, octopamine (OA), structurally and functionally similar to noradrenalin (NA) in mammals (Roeder 2005), can mediate changes in behavioral state that often promote activity; for example, sensitization of reflex actions in locusts (Sombati and Hoyle 1984), aggressive state in crickets (Stevenson et al. 2005), initiation and maintenance of flight state (Brembs et al. 2007; Suver et al. 2012), and enhanced excitability of Drosophila motion detection neurons during flight (Strother et al. 2018). Another role of OA is as a reward signal: A single OA neuron, VUMmx1, mediates the reinforcing function of unconditioned stimulus in the honeybee proboscis extension reflex (Hammer 1993; Hammer and Menzel

\footnotetext{
${ }^{1}$ These authors contributed equally to this work.

Corresponding author: Im546@gen.cam.ac.uk

Article is online at http://www.learnmem.org/cgi/doi/10.1101//m.052159.120.
}

1998; Menzel 2012). In Drosophila, acquisition of appetitive memory is impaired in $T \beta H$ mutants, unable to synthesize OA (Schwaerzel et al. 2003), and activation of OA neurons can substitute reinforcing stimulus in appetitive learning (Schroll et al. 2006). Moreover, OA receptors are necessary for reward learning in Drosophila (Burke et al. 2012) and crickets (Matsumoto et al. 2015).

To understand the neural mechanisms of OA in higher order sensory discrimination, we used the simple sensory "cortex" of larval Drosophila, the calyx, which is the sensory input region of the mushroom bodies (MBs), the insect memory center. Here, each MB neuron (Kenyon cell [KC]) typically arborizes in several glomeruli, most of which are organized around the terminus of an olfactory projection neuron (PN); KCs thus combinatorially integrate multiple sensory input channels (Masuda-Nakagawa et al. 2005) and are coincidence detectors of multiple inputs. The APL provides inhibitory feedback (Lin et al. 2014; Masuda-Nakagawa et al. 2014) and helps to maintain KC sparse responses and odor selectivity (Honegger et al. 2011), analogous to inhibition in the mammalian PCx (Poo and Isaacson 2009; Stettler and Axel 2009; Gire et al. 2013). Thus, odors are represented as a sparse ensemble of KCs that are highly odor selective, a property beneficial for memory (Olshausen and Field 2004).

In addition, the larval $\mathrm{MB}$ calyx is innervated by two OA neurons, sVUMmd1 and sVUMmx1, ventral unpaired medial neurons with dendritic fields originating in the mandibular and maxillary neuromeres, respectively, of the SEZ in the third instar larva

(C) 2021 Wong et al. This article is distributed exclusively by Cold Spring Harbor Laboratory Press for the first 12 months after the full-issue publication date (see http://learnmem.cshlp.org/site/misc/terms.xhtml). After 12 months, it is available under a Creative Commons License (AttributionNonCommercial 4.0 International), as described at http://creativecommons. org/licenses/by-nc/4.0/. 
(Selcho et al. 2014). sVUMmd1 and sVUMmx1 are named as OANa-1 and OANa-2, respectively, in the EM connectomic analysis of a 6-h first instar larva (Eichler et al. 2017; Supplemental Fig. 3 of Saumweber et al. 2018). These sVUM1 neurons also innervate the first olfactory neuropile of the antennal lobe (AL). This pattern of innervation is conserved in other insects, for example, the dorsal unpaired median (DUM) neurons in locusts (for review, see Bräunig and Pflüger 2001), the VUMmx1 neuron in honeybees (Hammer 1993; Schröter et al. 2007), and OA-VUMa2 neurons in adult Drosophila (Busch et al. 2009). In adult Drosophila, OA-VUMa2 neurons also show a dense innervation of the lateral horn, implicated in innate behaviors (Busch et al. 2009). The widespread innervation of the insect olfactory neuropiles also resembles the widespread NA innervation of mammalian olfactory processing areas, such as the olfactory bulb, and piriform cortex, by LC neurons originating in the brainstem.

We characterized the innervation pattern and synaptic targets of sVUM1 neurons in the calyx, with MB intrinsic and also extrinsic neurons, the localization of the OA receptor Oamb in the calyx circuit, and the impact of sVUM1 neuron activation on behavioral odor discrimination. For this we used an appetitive conditioning paradigm, and tested the ability of larvae to discriminate between similar odors, as opposed to dissimilar odors. Since the larval connectome is based on a single brain, at first instar stage before octopaminergic connections have become as extensive as at third instar, and to obtain a comprehensive understanding of the synaptic targets of sVUM1s in the third-instar larval calyx, we extended our analysis to previously unanalyzed connectivity of VUM1s, to APL and PNs. Further, we combined light microscopy of third-instar larvae with the connectome described by Eichler et al. (2017).

We find that sVUM1 neurons in third-instar larvae contact all the major classes of calyx neuron to some degree, consistent with EM synaptic analysis of the 6-h larva (Eichler et al. 2017). A GFP fusion of the OA receptor Oamb is localized in the terminals of PNs, and activating a subset of five SEZ neurons, including sVUM1 neurons, can affect discrimination of similar odors, without affecting underlying olfactory learning and memory ability. We suggest a broad modulatory effect of sVUM1 neurons in the calyx, including a potential role in modulating $\mathrm{PN}$ input at the second synapse in the olfactory pathway.

\section{Results}

\section{sVUM1 neurons in the third-instar calyx and their polarity}

\section{Two OA neurons innervate throughout the calyx without obvious regional preference}

At the third-instar stage, the larval calyx is innervated by two classes of OA neurons, sVUMmd1 and sVUMmx1, originating from the mandibular and maxillary neuromeres, respectively, in the subesophageal zone (SEZ), and labeled by the Tdc2-GAL4 line (Selcho et al. 2014). These neurons are named OANa-1 and OANa-2, respectively, in the 6-h larval brain EM connectomic analysis, described by Eichler et al. (2017). OAN-a1 corresponds to VUMmd1, and $\mathrm{OAN}-\mathrm{a} 2$ to VUMmx1, judging from the respective anterior and posterior positions of their cell bodies in Extended Figure 5 of Eichler et al. (2017). Both neurons are labeled by GMR34A11-GAL4 (Supplemental Fig. 3 of Saumweber et al. 2018), which we used below in our behavior analysis. To visualize the innervation pattern of these neurons together in the more mature third-instar larva, we used the Multicolor FlpOut technique (Nern et al. 2015). Flies of genotype pBPhsFlp2::PEST(attP3); HA_V5_FLAG_OLLAS were crossed to flies of $T d c 2$-Gal4, and single cell clones were generated by heat shock. Each sVUM1 neuron ramified throughout the calyx, and we only ever found a single sVUMmd1 or sVUMmx1 neuron labeled. When both sVUM1 neurons were labeled, they ramified through the calyx in a nonoverlapping pattern; no fasciculation between the processes of the two neurons was observed, and each innervated the whole calyx without obvious regional preference, as shown in the 3D image (Fig. 1A). Two cell bodies were labeled in the same channel in the mandibular neuromere, but only one innervated the calyx. A single sVUM1 neuron was identifiable by labeling in a single channel in the maxillary neuromere (Fig. 1B).

Cell bodies of sVUM1 neurons are at the midline of the CNS in the SEZ; their primary processes project dorsally and bifurcate just before the esophagus foramen, to generate two laterally oriented

A

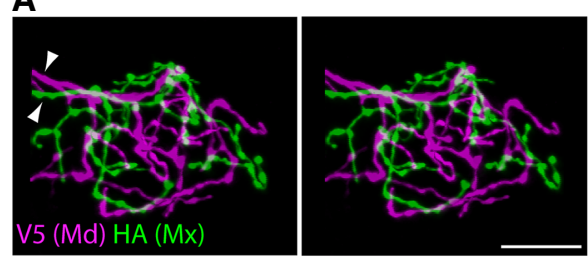

B

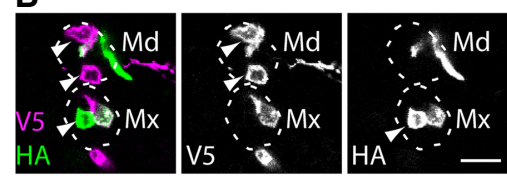

C

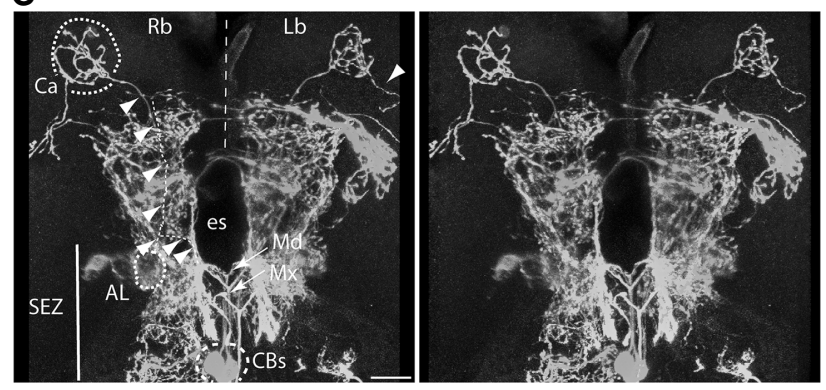

Figure 1. Multicolor FlpOut of Tdc2-GAL4-expressing neurons labels two calyx-innervating neurons in third-instar larvae. $(A-C)$ Clones of larvae of genotype $w$, pBPhsFlp2::PEST; Tdc2-GAL4; UAS-Ollas (attP2) UAS-HA-UAS-V5-UAS-FLAG (attP1), were generated by heat shock induction of FLP, and identified by multicolor labeling. (A) 3D stereo pair of images of an sVUM1Md neuron (V5 tag) and an sVUM1Mx neuron (green, HA tag), both ramifying throughout the calyx. Arrowheads show the axons of the two neurons. Scale bar, $10 \mu \mathrm{m}$. (B) Cell bodies in the SEZ of the same larva. In the mandibular (top) neuromere, two cell bodies labeled in magenta can be identified labeled by antibody to V5 (arrowheads). One of these is the sVUM1md neuron. In the maxillary (bottom) neuromere, a single cell body is only green, identified by anti-HA (arrowhead). (C) 3D stereo pair of images of a frontal view of a larva in which neurons are clonally labeled with anti-V5, for anatomical clarification. An sVUM1 neuron trajectory is shown. Cell bodies (CBs) of sVUM1 neurons are at the ventral midline of the subesophageal zone (SEZ). Each sVUM1 neuron sends a primary process that bifurcates into secondary processes at the level of the mandibular (Md, arrow) for sVUM1Md, and maxillary (Mx, arrow) neuromere for sVUM1Mx. Each secondary process joins an ascending tract on each side of the esophagus foramen (es) to innervate the ipsilateral protocerebrum, right brain (Rb), or left brain (Lb). While one branch innervates the AL (antennal lobe), another branch separates to follow a tract to the calyx (Ca). $\mathrm{Ca}$ and $\mathrm{AL}$ are indicated by dotted lines. The AL can be appreciated at the ventral-anterior region of the brain in the 3D. An arrowhead shows a ventral protrusion from the calyx. The trajectories of the VUM neurons are labeled by arrowheads and smaller dotted lines. Scale bars: $A, B, 15$ $\mu \mathrm{m} ; \mathrm{C}, 20 \mu \mathrm{m}$. 
secondary processes, each of which joins an ascending tract to the protocerebrum on each brain hemisphere. At the posterior of the $\mathrm{AL}$, the process generates a branch that goes anteriorly and ramifies in the AL. The main branch ascends through the inner antennocerebral tract to reach the calyx at the dorsal protocerebrum. One branch emanates from the calyx and projects ventrally, presumably to the lateral horn (Fig. 1C).

\section{OA neurons are presynaptic in the calyx}

To visualize the polarity of the calyxinnervating sVUM1 neurons, we used Tdc2-GAL4 to express either plasma membrane, presynaptic or dendritic markers (Fig. 2). The projections of both sVUMmd1 and sVUMmx1, when visualized by the plasma membrane marker CD4::tdTom, showed dense ramification throughout the calyx, with discrete and abundant bouton-like enlargements along the axonal process, predominantly among glomeruli and in the core of the calyx (Fig. 2A). The presynaptic nature of the Tdc2-GAL4-expressing calyx boutons was further supported by the localization of the presynaptic markers nSyb:: GFP (Fig. 2A) and Syt::GFP (Fig. 2B), prominently between glomeruli or in the nonglomerular core of the calyx. Only a few dots are visible of the dendritic marker DenMark (Fig. 2B) in the terminals throughout the calyx. On the other hand, DenMark::mCherry is strongly localized in the SEZ region (Fig. 2C), where the postsynaptic processes of VUM neurons are localized. The DenMark: mCherry labeling includes dense arborizations of other Tdc2-GAL4-expressing neurons as well as of the sVUM1 neurons. The innervation of the calyx by $T d c 2$ neurons can be visualized in Figure 2D.

\section{Identifying third-instar calyx $\mathrm{OA}$ neuron partners}

To obtain a comprehensive synaptic connectivity between sVUM1 neurons and intrinsic as well as all extrinsic neurons innervating the calyx, we used Tdc2-LexA, along with GAL4 lines expressing in other calyx neurons, to drive the expression of the GFP reconstitution across synaptic partners (GRASP) (Gordon and Scott 2009) constructs LexAop-CD4::spGFP11 and UAS-CD4::spGFP1-10 (Fig. 3). We labeled olfactory PNs using NP225-GAL4 (Tanaka et al. 2004), and KCs using Mef2GAL4 (Zars et al. 2000). We also tested for GRASP between sVUM1 neurons and two other classes of extrinsic calyx neurons. First, we labeled the larval APL using NP2361-GAL4 (Masuda-Nakagawa et al. 2014). Second, two of the "Odd" class of neurons that arborize throughout the ca-

B $10 \mu \mathrm{m}$.
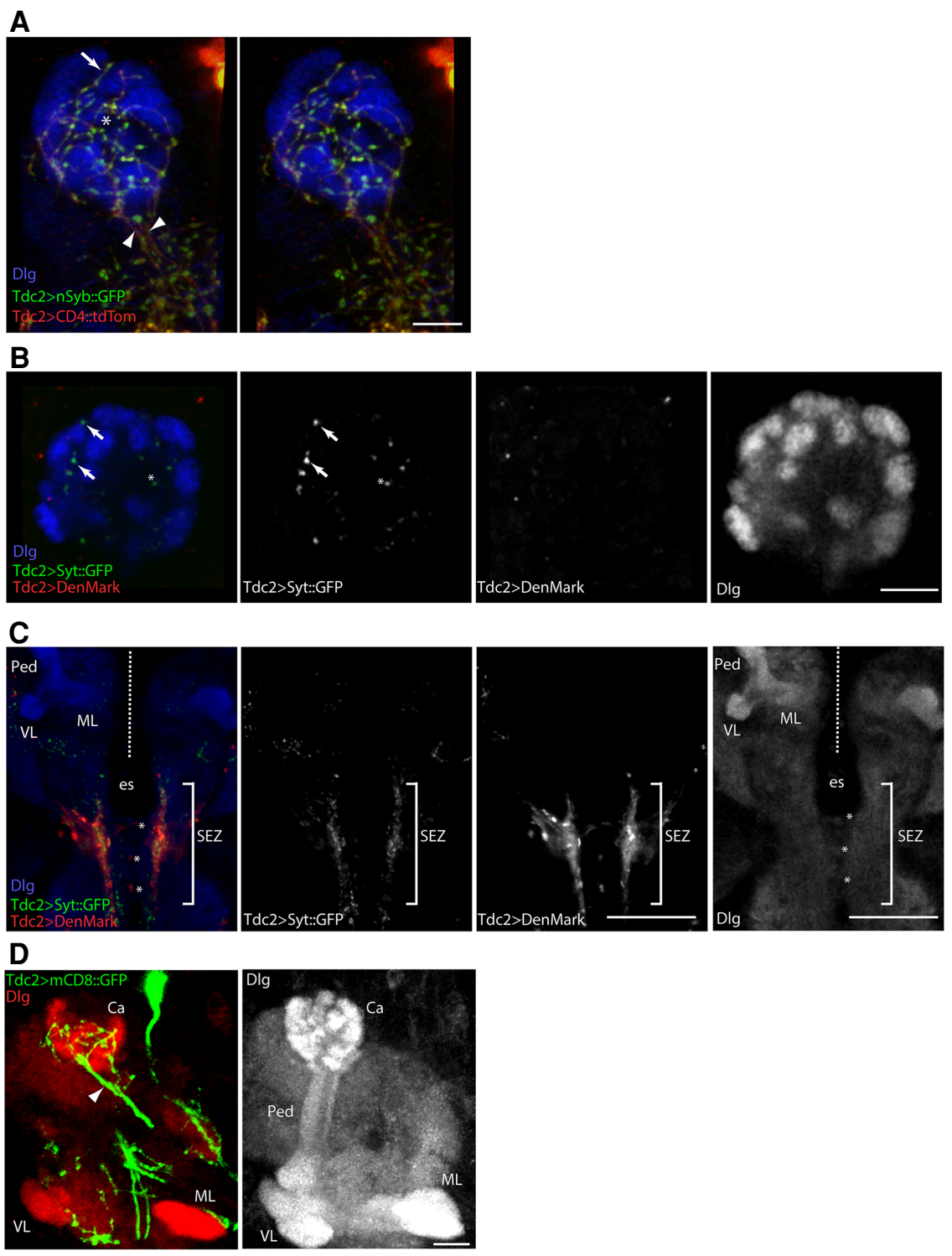

Figure 2. Polarity of calyx innervation by $T d c 2-G A L 4$-expressing neurons in third-instar larvae. $(A) 3 D$ stereo pair of images of a third-instar calyx expressing nSyb::GFP and CD4::tdTom using Tdc2-GAL4, obtained from a cross between UAS-CD4::tdTomato (II); UAS-nSyb::GFP (III), and Tdc2-GAL4 parents. Two axonal tracts (arrowheads) enter the calyx and ramify throughout it (CD4::tdTom), while processes show nSyb::GFP in boutons (green). Note boutons at the borders of glomeruli (e.g., arrow; glomeruli labeled with anti-Dlg) and core of the calyx (e.g., asterisk). (B) Confocal section of a larval calyx expressing DenMark::mCherry and Syt::GFP using Tdc2-GAL4, obtained from a cross of genotype Tdc2-GAL4 to BDSC stock 33065 . Note the almost complete absence of DenMark::mCherry within the calyx. Asterisk indicates the core of the calyx with adjacent Syt::GFP puncta. Arrows indicates Syt::GFP boutons between glomeruli. $(C)$ Confocal section of a larval brain expressing Syt::GFP and DenMark::mCherry using Tdc2-GAL4. The primary processes of Tdc2-GAL4-expressing neurons in the SEZ are shown (asterisks). Brain neuropiles are labeled by Dlg. (Dotted line) Midline of the CNS between right and left brain hemispheres, (es) esophagus, (VL) MB vertical lobe, (ML) MB medial lobe, (SEZ) subesophageal zone (brackets). (D) Frontal view of a right brain hemisphere, showing an $\mathrm{MB}$ calyx innervated by Tdc2-GAL4 driving expression of mCD8::GFP. (Left) Projection of six sections showing the Tdc2-GAL4 tract entering the calyx ( $\mathrm{Ca}$, arrowhead). (Right) The same projection of the MBs labeled by Dlg (right brain hemisphere). Notice the glomerular structure of the calyx. $(A, B)$ Anterior to the bottom, medial to the right, right brain orientation. Scale bars, $10 \mu \mathrm{m}$. $(C)$ Ventral view, anterior to the top. Scale bar, $50 \mu \mathrm{m}$. (D) Frontal view, anterior to the bottom, medial to the right, right brain. Scale bar,

lyx (Slater et al. 2015) have been designated MBON-a1 and MBON-a2 by Eichler et al. (2017); we identified a GAL4 line, OK263-GAL4, which expresses in these neurons. 

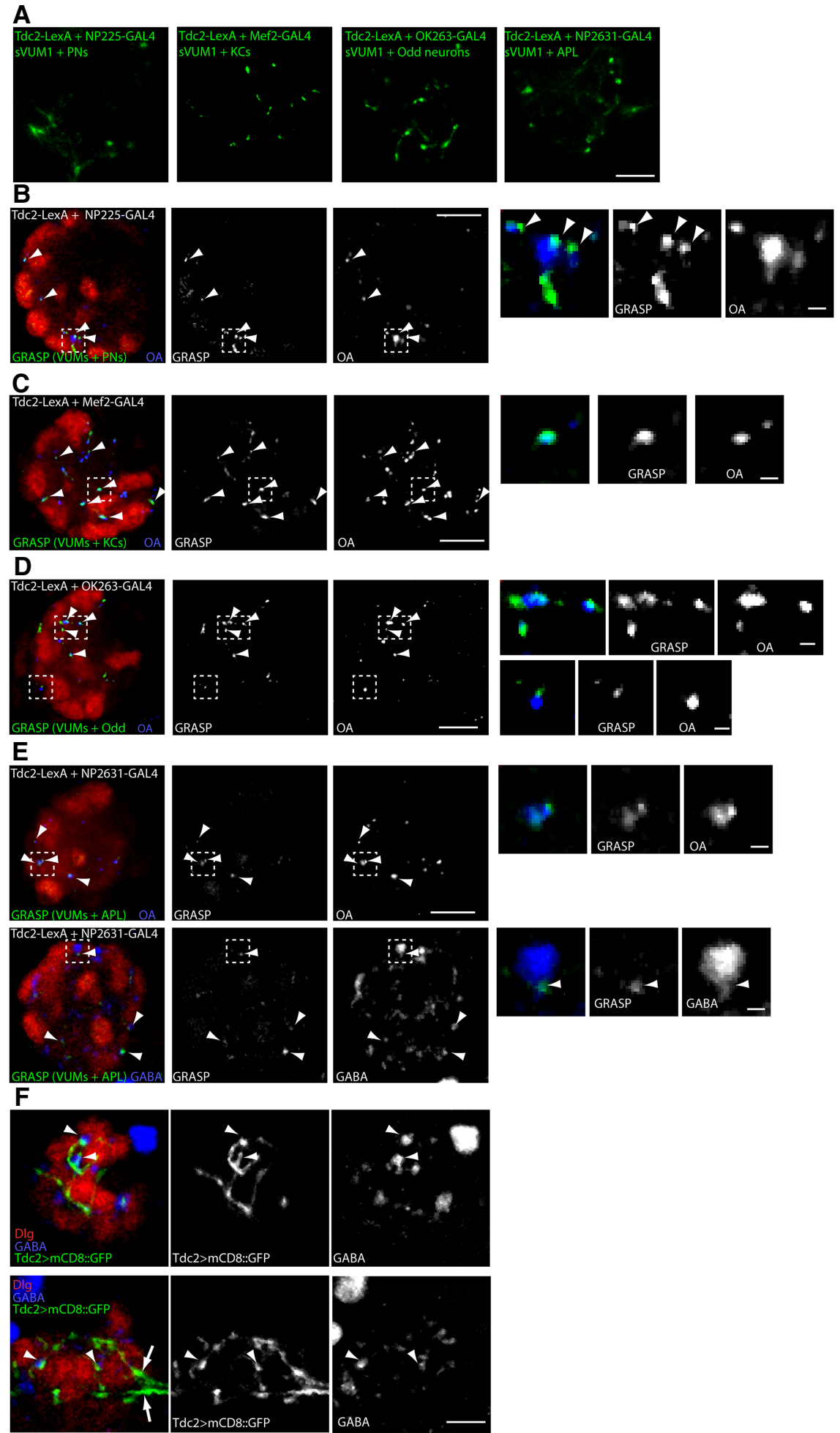

Figure 3. GRASP shows calyx contacts of sVUM1 termini with PNs, larval APL, and Odd neurons, and few KCs. A line carrying GRASP constructs UAS-CD4::spGFP1-10 and LexAop-CD4::SpGFP11, was crossed to each of the following lines as needed: NP225-GAL4(II); Tdc2-LexA(III), OK263-GAL4(II); Tdc2-LexA(III), NP2631-GAL4(II); Tdc2-LexA(III), or Tdc2-LexA(II); Mef2-GAL4(III), and GRASP signals were detected in the larval progeny. (A) GRASP signal between sVUM1 neurons (expressing TdC2-LexA) and other calyx neurons expressing the GAL4 lines shown, is detected as native GFP fluorescence in confocal sections. Scale bar, $10 \mu \mathrm{m}$. (B-E) GRASP signal between sVUM1 neurons (expressing Tdc2-LexA) and other calyx neurons expressing the GAL4 lines shown, detected by rat monoclonal anti-GFP. Examples of GRASP signal are highlighted with arrowheads; areas inside broken square are shown at higher magnification. sVUM1 termini are labeled using anti-OA, calyx glomeruli using anti-Dlg. Scale bars here and throughout figure: in main panels, 10 $\mu \mathrm{m}$; in insets, $1 \mu \mathrm{m}$. (B) GRASP signal between sVUM1 termini and PNs, localized mainly around glomeruli. OA signals without GRASP are localized to the calyx core. Examples of GRASP signal are highlighted with arrowheads. (Inset) GRASP signal overlaps partially with sVUM1 termini labeled with OA. Areas inside broken lines, here and subsequently, are shown at higher magnification. (C-E) GRASP signals between sVUM1 termini and KCs (C), Odd neurons $(D)$, or the APL neuron (E). (E) GRASP signals between SVUM1 and APL neurons are localized around glomeruli, or in the core of the calyx. The top panels show the extent of GRASP overlap with OA-containing sVUM1 terminals. The bottom panels show some GRASP signals overlapping partially with large GABA boutons. $(F)$ Confocal sections of a third-instar calyx expressing mCD8::GFP using Tdc2-Gal4, labeled with anti-GABA and anti-Dlg. Top is a dorsal section of calyx, bottom is a ventral section of the same calyx. Arrowheads indicate GABA boutons apposed to or overlapping with $T d c 2$ neuron terminals. Arrows indicate the two axonal tracts of $T d c 2$ neurons innervating the calyx. 


\section{GRASP fluorescence}

We detected GRASP using GFP fluorescence as widely distributed puncta in the calyx, in live images of brains, suggestive of specific synaptic connections, between the sVUM1 neurons on the one hand, and PNs, KCs, the Odd, and APL neurons on the other (Fig. 3A). Control crosses expressing the GRASP constructs under control of either a GAL4 or LexA calyx driver alone showed almost no GRASP puncta (Supplemental Fig. S1), showing the specificity of our rat monoclonal anti-GFP for reconstituted GFP. These findings suggest that at the third-instar larva, the sVUM1 neurons may form synapses with all the neuronal classes that innervate throughout the calyx: PNs, KCs, the APL, and Odd neurons.

To test whether GRASP signals represented synaptic contacts of the sVUM1 neurons, we also immunolabeled brains with anti-OA. GRASP signals were identified using a criterion that each GFP signal was observed in at least two consecutive confocal sections, and discounting occasional GFP-positive axonal tracts that were negative for OA. As noted below, the large majority of GFP puncta either overlapped or were directly apposed to OA signals, suggesting that GFP puncta were mostly or entirely specific for synaptic contacts, and did not form widely at nonsynaptic contacts.

\section{OA termini synapse with PNs}

Using Tdc2-LexA and NP225-GAL4 to express the GRASP constructs, we found GRASP signal at $49 \% \pm 3 \%$ of $80 \pm 4 \quad(n=5)$ OA-positive boutons. OA-positive GRASP signals (Fig. 3B) were found in the core of the calyx away from glomeruli, in interglomerular spaces, and along the periphery of glomeruli. They are likely contacts between sVUM1 termini and PN axons. Almost all GFP puncta $(87 \% \pm 2 \%, n=5)$ overlapped with or were apposed to OA boutons and are therefore potential synaptic contacts of the sVUM1 neurons; the remaining 13\% could represent nonsynaptic contacts, or synapses of PNs onto postsynaptic sites on the sVUM1 neurons. Therefore, PNs are commonly postsynaptic to the termini of sVUM1 neurons, on their axonal or presynaptic processes, making axon-axon synapses.

\section{OA termini synapse with $K C s$ in the calyx}

Using Tdc2-LexA and MB247-GAL4 to express the GRASP constructs, we found GRASP signals at $51 \% \pm 4 \%$ of $185 \pm 34(n=3)$ OA boutons in each calyx (Fig. 3C). GRASP puncta overlapping with $\mathrm{OA}$ were found in the interglomerular space. Again, most GFP puncta $(86 \% \pm 1 \%)$ overlapped with or were apposed to OA. Since third-instar larvae are estimated to have 250-300 KCs per brain hemisphere (Pauls et al. 2010), our data suggest that sVUM1 neurons together synapse onto up to about one-third of third-instar KCs.

\section{OA termini synapse with Odd neurons in the calyx}

Using Tdc2-LexA and OK263-GAL4 to express the GRASP constructs, we found GRASP signals at $51 \% \pm 0.3 \%$ of $124 \pm 4(n=3)$ OA labeled boutons (Fig. 3D). Again, the majority of GFP puncta $(80 \% \pm 1 \%)$ overlapped with or were apposed to OA, suggesting that Odd neurons are mostly postsynaptic to sVUM1s.

\section{OA termini synapse with the APL}

Using Tdc2-LexA and NP2361-GAL4 to express the GRASP constructs, we found GRASP signal at $77 \% \pm 4 \%$ of $74 \pm 12(n=4)$ OA terminals, indicating that sVUM1 neurons are presynaptic to the larval APL (Fig. 3E top panels). Most of these GRASP signals were found between glomeruli, and more abundant toward the ventral calyx.
Around $67 \% \pm 3 \%$ of GFP $(n=3)$ signals overlapped with OA, and therefore likely represent synapses of the sVUM1 neurons onto the APL. A higher frequency of GFP puncta did not overlap with OA $(33 \% \pm 3 \%)$ than was the case for other calyx neurons; this could potentially be due to synapses of the APL onto OA neuron axons. In support of this, we found some GABA termini in close proximity to GRASP (Fig. 3E, bottom panels); labeling of Tdc2-GAL4>mCD8::GFP calyces with anti-GABA also showed some apposition of sVUM1 boutons to GABAergic termini of the APL (Fig. 3F).

\section{Single-cell GRASP}

While the above GRASP experiments reveal the partners of the sVUM1 neurons in the calyx, they do not reveal whether the sVUMmd1 and sVUMmx1 have different partners. We therefore performed single-cell GRASP to label the contacts of each sVUM1 randomly, using Brp::mCherry as a presynaptic marker to verify whether GRASP signals have a synaptic localization. We distinguished the two sVUM1 neurons by the positions of their cell bodies in the SEZ, using local neuropil landmarks revealed by anti-Dlg labeling (Fig. 4A), and using single cell clones, we could identify sVUMmd1 and sVUMmx1 individually (Fig. 4B).

GRASP signals were detected between the Odd neurons and both sVUMmd1 and sVUMmx1 (Fig. 4C), and similarly between the larval APL, and both sVUMmd1 and sVUMmx1 (Fig. 4D). Compared with standard GRASP, single cell GRASP signals were fewer, but clearly present and overlapping with the presynaptic marker Brp::mCherry (Fig. 4D). The main targets of VUMmd1 and VUMmx1 in the olfactory pathway are the antennal lobe (AL), and calyx, as described in Selcho et al. (2014). There is also a prominent branch innervating the basolateral protocerebrum (anteromedial to the $\mathrm{AL}$ ) around the ventral midline at the esophagus foramen (as defined for adult flies, Busch et al. 2009) in the brain. Therefore, at least as judged by the APL and Odd neurons, both sVUM1 neurons appeared to have similar targets in the calyx.

\section{Comparison with first instar larva calyx synapses}

The enlargements seen using synaptic markers in Figure 2A contained OA (Fig. 3), therefore they are presynaptic boutons. Using the online publicly available first instar connectome (https ://11em.catmaid.virtualflybrain.org) on the Virtual Fly Brain site (Osumi-Sutherland et al. 2014; Cantarelli et al. 2018), we analyzed the synapse distribution and synaptic partners of the sVUM1 neurons specifically in the first instar larva calyx, not previously analyzed. We generated a tracing representation of the sVUM1 neurons (Fig. 5A,B) using the 3D tool of the publicly available CATMAID software. While the growth, morphology, and anatomical organization of the two sVUM1 neurons is similar to the anatomical organization of the third-instar larvae, the arborizations in the calyx are fewer in the first instar compared with third-instar larvae. In our GRASP analysis, we observed $89 \pm 7$ (mean \pm SEM; $n=$ 12) OA-positive boutons per calyx for both sVUM1 neurons, compared with 28 presynaptic synapses marked in the left brain calyx, and around 39 in the right brain calyx in the single 6-h larva brain connectome (Fig 5C,D).

Moreover, the number of connections between sVUM1 and other neurons was substantially lower at the first instar compared with the third-instar stage (Supplemental Table S1), with the firstinstar brain having $<50 \%$ of synaptic numbers per calyx per neuron type compared with the third-instar brain.

Given the GRASP signals at sVUM1 synaptic termini, we predicted that we might find the same sVUM1 synaptic targets in the first-instar calyx connectome. Eichler et al. (2017), reported synapses of sVUM1 onto the Odd neurons, and a small fraction of 
A
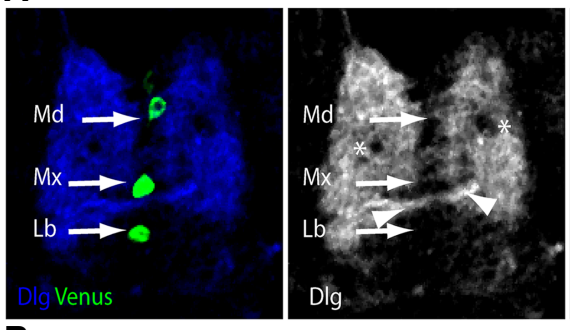

$\bar{B}$
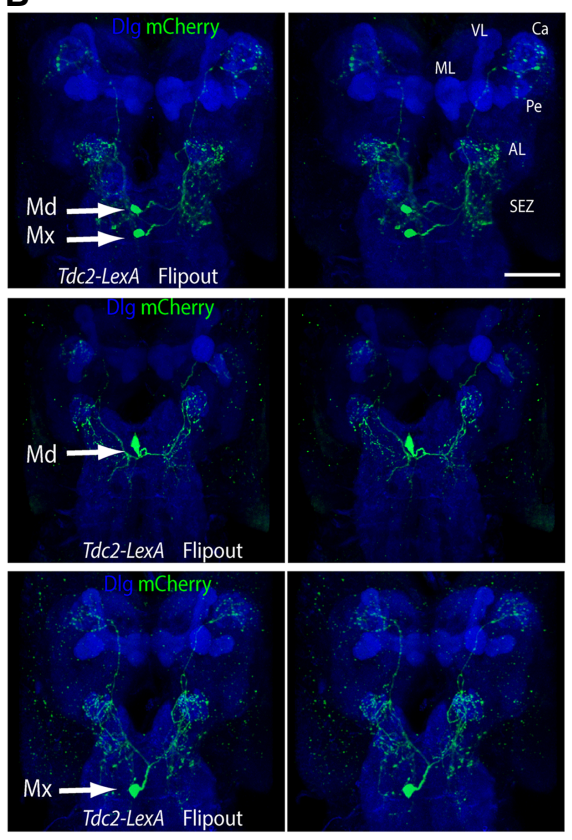

C

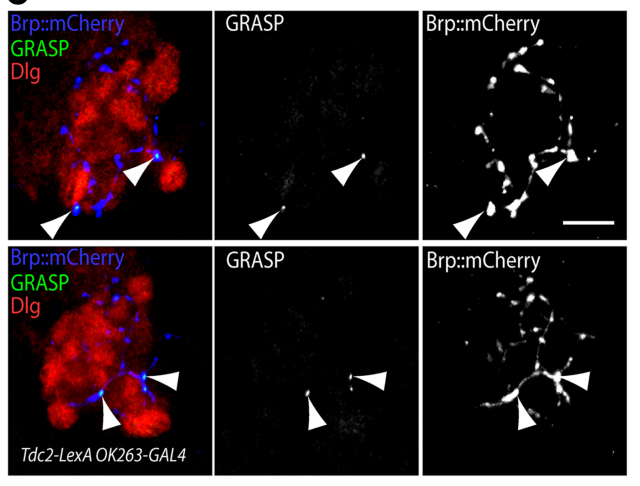

D
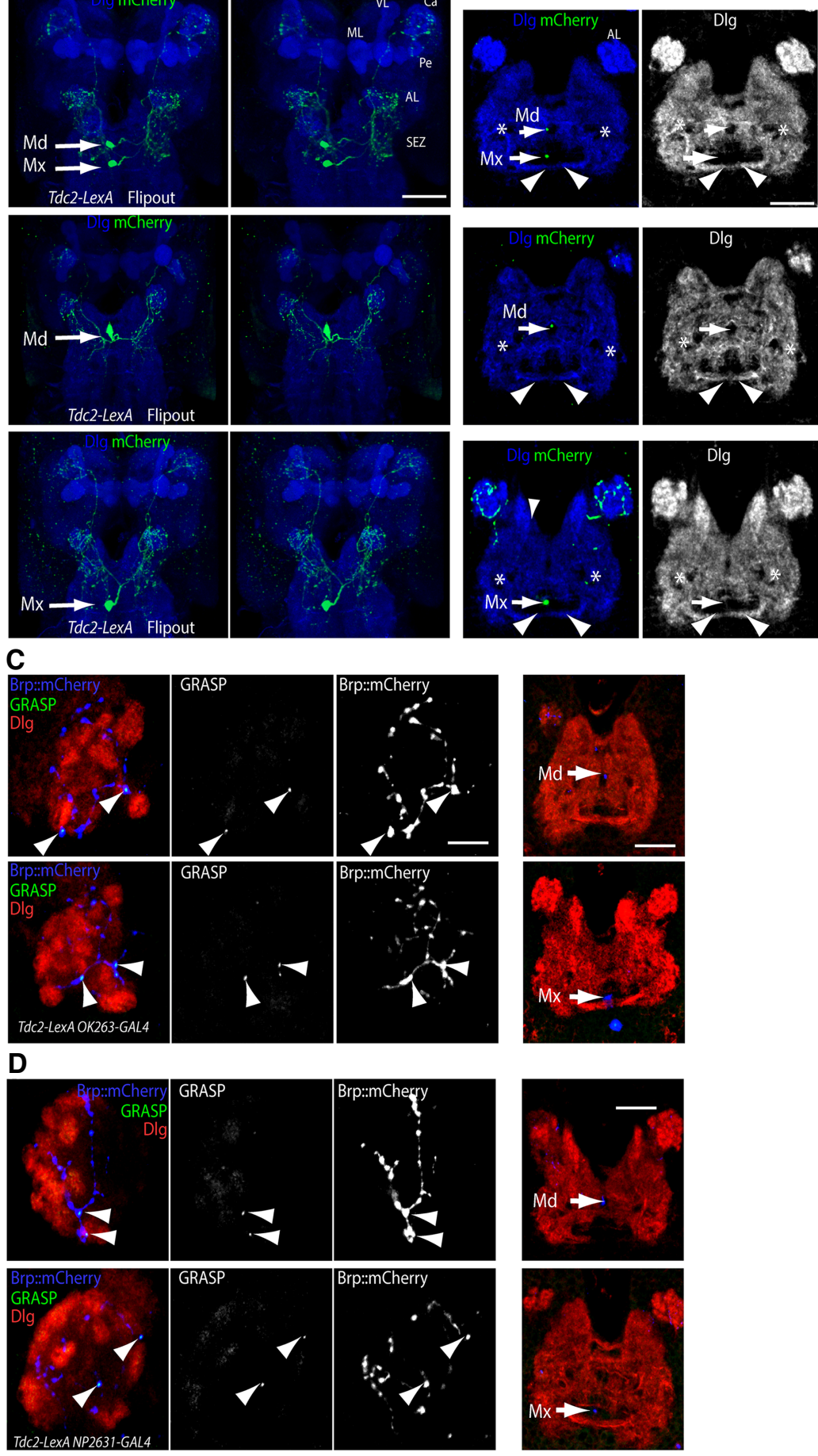

Dilg
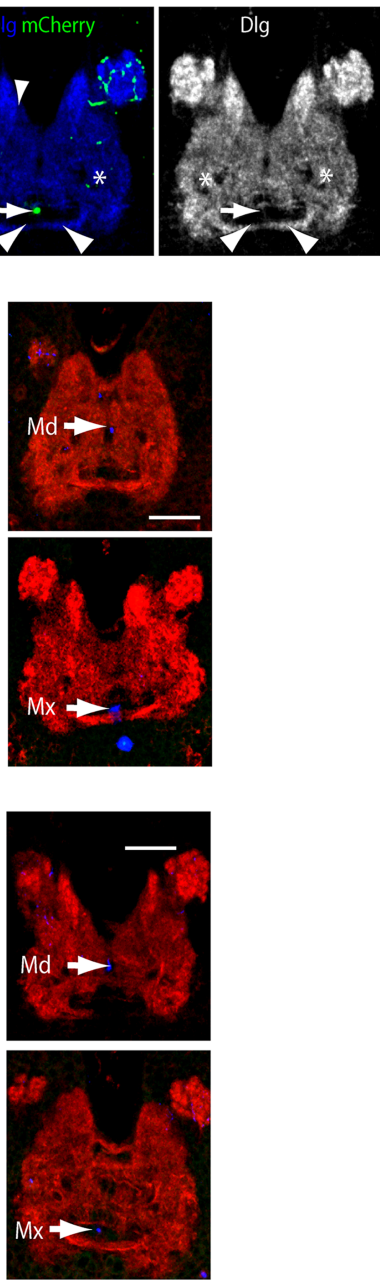

Figure 4. (Legend on next page)
KCs. We found examples of these synapses, and additionally, synapses not yet described between sVUM1 neurons onto PNs and the APL neuron (Fig. 5E). In addition to the apparently simple synapses of sVUM1 neurons onto PNs, KCs, Odd neurons, and the APL, we sometimes found adjacent synaptic contacts of either sVUM1 neuron onto both an Odd neuron and the APL (Fig. 5E), suggesting locally coordinated circuit regulation of both these neurons by the sVUM1 neurons. Clear vesicles and typical synaptic bars were present in sites of connectivity between sVUM1s and other neurons (Fig. $5 \mathrm{E})$, supporting a synaptic release of octopamine. Although sVUM1s also contain dense core vesicles, our studies did not address whether sVUMs release neuropeptides.

Localization of a genomic Oamb:: GFP fusion in PN terminals in calyx To further understand how and where $\mathrm{OA}$ might act in the calyx, we investigated the localization of $\mathrm{OA}$ receptors in the calyx. Drosophila has a number of OA receptor classes defined both by sequence comparisons and pharmacology. Octopamine receptor in mushroom bodies (Oamb, also known as Dmoa1A or CG3856), an ortholog of human $\alpha 1$-adrenergic receptor (Roeder et al. 2003; Bauknecht and Jékely 2017), is enriched in the MBs (Han et al. 1998). Drosophila also has three OctßR receptors, which stimulate cAMP levels (Balfanz et al. 2005; Maqueira et al. 2005).

To detect the expression and subcellular localization of Oamb, we used recombinase-mediated cassette exchange (RMCE) with a MiMIC insertion (Venken et al. 2011), MI12417, in the third codingregion intron of $O a m b$, to tag endogenous Oamb with an exonic EGFP-FlAsH-StrepIITEV-3xFlag fusion (Supplemental Figs. S2-S5). Insertion of an EGFP-encoding exon here should tag all known splice variants of the Oamb protein in their third cytoplasmic loop, downstream from transmembrane (TM) domain 5 (Supplemental Figs. S6, S7); this includes the alternative TM6-TM7 regions encoded by two alternative groups of C-terminal exons (Supplemental Figs. S5-S7). Therefore, a protein trap generated from the MI12417 insertion will not disrupt any transmembrane domains.

Six recombinant Oamb::EGFP stocks were recovered with the EGFP-encoding exon inserted in the same orientation as the Oamb transcript (Supplemental Fig. 7). One of these was designated as $\mathrm{Mi}$ \{PT-GFSTF.1\}Oamb MII2417-GFSTF.1, $^{\text {or }}$ Oamb(MI12417)::EGFP.1 or Oamb::EGFP 
for short. Both the original MI12417 MiMIC insertion, and Oamb (MI12417)::EGFP stocks were homozygous infertile, as expected from the egg-laying defects of Oamb mutants (Deady and Sun 2015), suggesting that the Oamb::EGFP fusion might not be a functional Oamb protein. However, Oamb::EGFP was localized to glomeruli in the larval calyx (Fig. 6), implying that the protein folded normally and was not degraded by the ER unfolded protein response. Expression of UAS-RFP in the olfactory PN line NP225-GAL4 showed localization of Oamb::EGFP in all PN termini labeled with the GAL4 line, as well as in some calyx glomeruli not labeled by NP225-GAL4, which may be either sites of nonolfactory sensory input, or olfactory glomeruli not labeled by NP225-GAL4 (Fig. 6A). The restriction of Oamb::EGFP to specific glomeruli implies that it is unlikely to be expressed in KC dendrites in the calyx, which arborize through all glomeruli. We also found no overlap of Oamb::EGFP with GABAergic APL terminals in the calyx (Fig. 6B), implying that it was not expressed in the larval APL. OK263-GAL4 calyx projections also showed little or no overlap with Oamb:: EGFP (Fig. 6C), suggesting that Oamb is not expressed in the Odd neuron calyx dendrites.

In the olfactory pathway Oamb::EGFP was detected diffusely in the AL. Cell bodies of PNs labeled by NP225-GAL4>mCD8:: $R F P$ also expressed Oamb::EGFP (Fig. 6D), and other neurons surrounding the AL, but not labeled by NP225-GAL4> mCD8::RFP, expressed Oamb::EGFP (Fig. 6D). These could be interneurons and potentially the main source of labeling in the AL. No distinct glomeruli were detected. Oamb::EGFP was detected in the lateral horn, along the lateral pedunculus, with strong expression toward the anterior lateral end, where a separate compartment along the pedunculus is labeled (Fig. 7A,B). Oamb::EGFP is detected around the medial lobe and the spur, spur as defined by Figure $6 \mathrm{E}$ of Younossi-Hartenstein et al. 2003 (Fig. 7C). This localization of Oamb::EGFP overlaps with innervation by Tdc2-GAL4-expressing neurons in the spur and around the ventral medial lobe (Fig. 7D).

We found no detectable localization of MiMIC GFP-tagged DmOct $\beta$ R receptors to the calyx (data not shown). Oct $\beta 1 R:: E G F P$ (CG6919) was detected weakly in a few ventral and medial AL glomeruli by a polyclonal anti-GFP, but was not detectable in the calyx. Oct $\beta 2 R:: E G F P(C G 6989)$, was not detectable in either the calyx or $\mathrm{AL}$, although it was expressed in a number of adjacent cell bodies that did not colocalize with PNs as labeled by NP225-GAL4 driving
RFP expression. We could not detect Oct $\beta 3 R:: E G F P$ anywhere in the brain, and therefore the fusion might not be expressed, or misfold and be degraded.

\section{Activating an OA neuron subset including sVUMl neurons impairs behavioral odor discrimination}

Since the calyx is a site where MB neurons process olfactory information that comprises conditioned stimuli in associative learning, we reasoned that modulating the processing of this information might affect the ability of the brain to discriminate among different conditioned stimuli representations while learning, but without affecting its underlying learning ability. Therefore, to test whether OA innervation of the calyx affected odor discrimination during learning, we developed an assay that could distinguish odor discrimination ability from learning ability (Fig. 8). The rationale of this assay was developed in the honeybee by Stopfer et al. (1997) in pattern recognition. Desynchronization of PN ensembles impaired fine discrimination of molecularly similar odors but not dissimilar odors. When bees are conditioned with one odor and sucrose, the conditioned response generalizes to structurally similar odors used for conditioning (Smith and Menzel 1989). Therefore, we reasoned that mixtures of two odors at different ratios would be more similar and harder to distinguish than the two pure constituent odors, and this would allow us to test changes in the degree of discrimination ability by activation of sVUM1 neurons; this rationale was used successfully by Lin et al. (2014). By combining odor choice with an appetitive learning paradigm (Scherer et al. 2003), we tested the effect on behavioral odor discrimination of optogenetic activation of OA neurons in third-instar larvae, using the long-wavelength absorbing channelrhodopsin, CsChrimson (Klapoetke et al. 2014).

Since we did not have GAL4 or LexA drivers completely specific for sVUM1 neurons, we used an intersectional approach to restrict the expression of CsChrimson to a small subset of OA neurons including the sVUM1 neurons. We could use LexAop-FLP and a GAL8O cassette flanked by two FRT sites to express UAS-CsChrimson only in neurons that expressed both GMR34A11-GAL4 (which labels some VUM neurons in addition to non-OA neurons), and Tdc2-LexA. We thus expressed CsChrimson in only five OA neurons in the SEZ of the larval brain: two in the mandibular neuromere (including sVUMmd1), two in the maxillary neuromere (including sVUMmx1), and one in the labial neuromere $(n=8)$ (Fig. 9A). The second neuron labeled in each neuromere could be the sVUM2, characteristic for the lateral branch innervating the optic lobe; the sVUM3, which innervates the dorsal medial protocerebrum and basal medial protocerebrum (Selcho et al. 2014); or an unidentified sVUM; however, sVUM1 neurons are the only neurons of this subset to innervate the AL and calyces.

Activation of these OA neurons by amber light, during conditioning, had no effect on the ability of larvae to discriminate odors in an appetitive odor discrimination learning assay using a dissimilar odor pair; however, it abolished their ability to discriminate a similar odor pair, suggesting that odor discrimination is affected by activation of these neurons, but not underlying learning ability (Fig. 9B). To exclude any effects of OA 

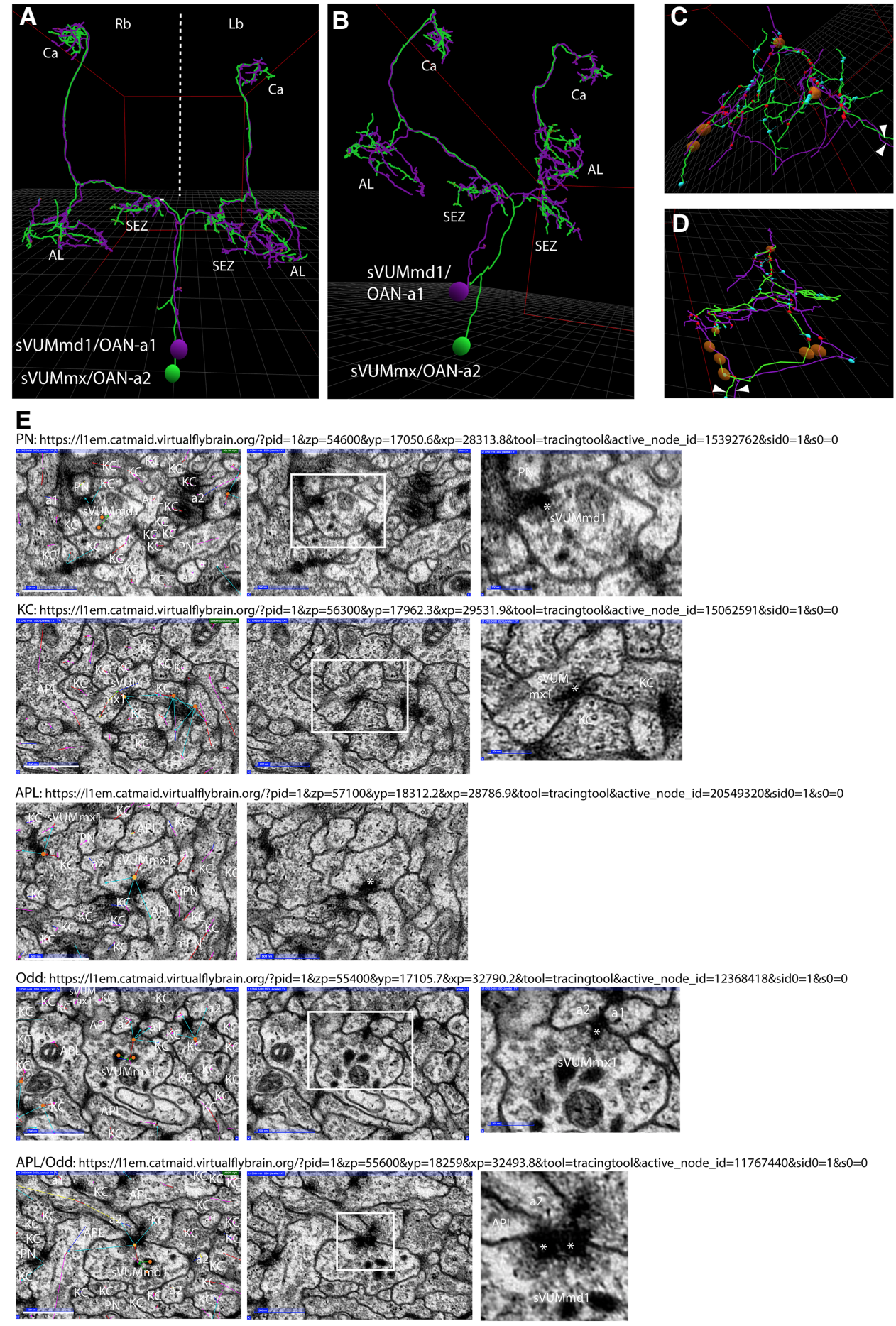

Figure 5. Synapses of sVUM1 neurons onto other first-instar calyx neurons. ( $A$ ) Ventral view of a reconstruction of sVUMmd1/OAN-a1 (magenta) and sVUMmx1/OAN-a2 (green), including their dendritic arborizations in the subesophageal zone (SEZ) and presynaptic terminals in the antennal lobe (AL) and calyx $(\mathrm{Ca})$. The right brain $(\mathrm{Rb})$ is to the left of the midline (dotted line), and left brain ( $\mathrm{Lb})$ to the right. sVUM1 neurons bifurcate at the midline and a single neuron innervates both brain hemispheres. $(B) A$ ventrolateral view of the same reconstructions as $A$. $(C, D)$ Reconstructions of sVUM1md1 and sVUMmx1 calyx projections in the right $(C)$ and left $(D)$ brain. Red circles are sVUM1 presynaptic termini (blue circles are postsynaptic sites). Note the 39 presynaptic terminals of sVUM1 neurons in the right calyx $(C)$ and the 28 presynaptic termini in the left calyx $(D)$. Brown circles are tracing sites not finished. Images were generated by analysis of neuron tracing using the 3D tool of CATMAID on the publicly available first-instar larval connectome on the Virtual Fly Brain site (https://11 em.catmaid.virtualflybrain.org; License CC-BY-SA_4.0). (E) EM sections of first-instar calyx (Eichler et al. 2017) showing synaptic partners of either sVUMmd1 or sVUMmx1, named as OAN-a1 and OAN-a2 by Eichler et al. (2017) and in CATMAID as "anterior ladder" and "posterior ladder" neurons, respectively. Sections were visualized using CATMAID software via the Virtual Fly Brain site. Each row shows a different example of postsynaptic target neurons: a PN, a KC, the APL (labeled in CATMAID as MBE12), Odd neurons (MBON-a1 and MBON-a2, labeled here as a1 and a2, and in CATMAID as MBE7a and MBE7b), and a tripartite synapse of an sVUM1 neuron on both an Odd neuron (MBON-a2) and the APL. In each row, the first (left) panel shows a section with CATMAID annotation, and the identities of neurons close to the sVUM1 neuron and its synaptic target. Notice the connector (orange-filled circle) placed on the sVUM1 neuron and the linked cyan arrows projecting to postsynaptic partners. Red arrows pointing to the connector indicate that the connector is on the presynaptic neuron. The second panel shows the same image with annotation omitted to allow better visualization. The third panel (where present) shows a magnified view of the inset in the middle panel; a presynaptic release site in the sVUM1 neuron, characterized typically by a T-bar and surrounding synaptic vesicles, is shown with an asterisk. Scale bars, $500 \mathrm{~nm}$. URLs link to the locations of images shown. 
A
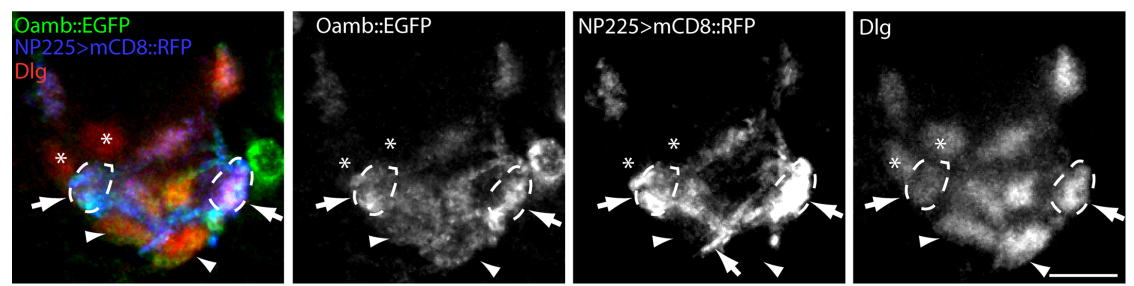

B
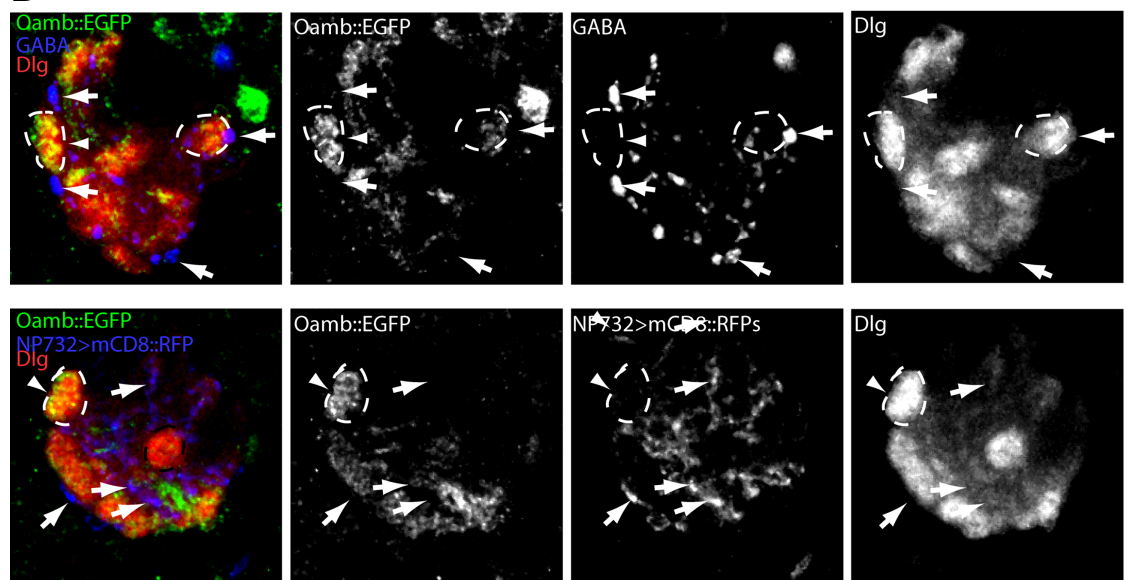

C

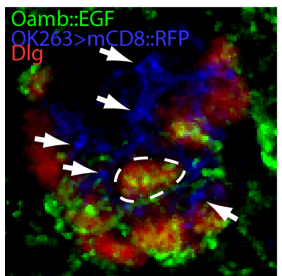

D

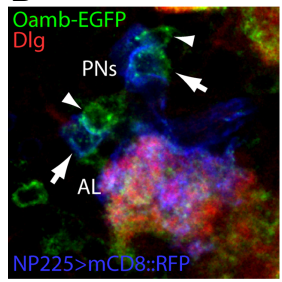

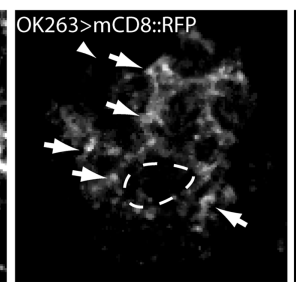
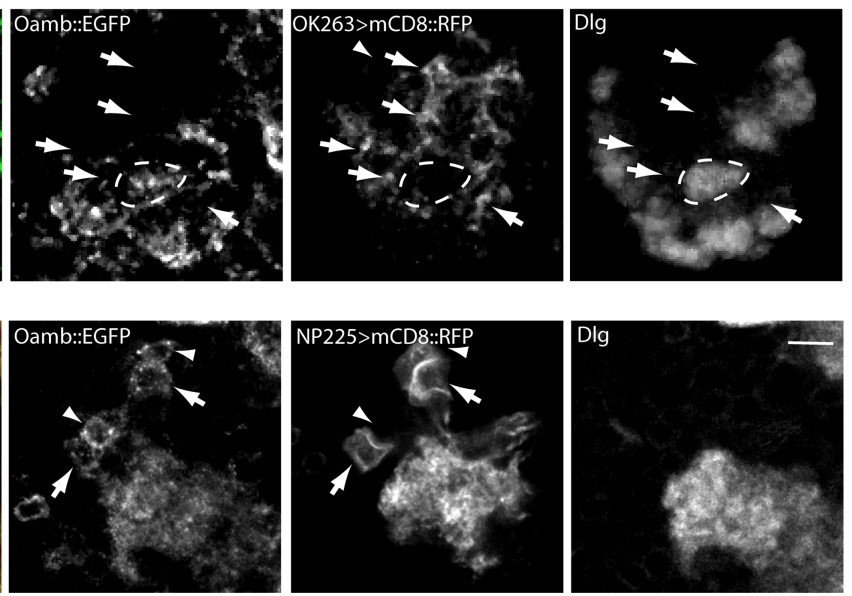

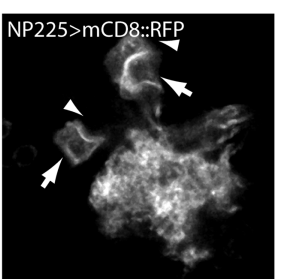

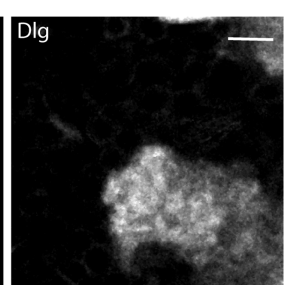

Figure 6. Oamb-EGFP localization in PN presynaptic termini. (A) Calyces of a larva carrying Oamb: EGFP, NP225-GAL4, and UAS-RFP labeled with chick polyclonal anti-GFP, anti-DsRed and anti-Dlg. Oamb::EGFP localizes to PN terminals in all glomeruli labeled by NP225-GAL4 (arrows), and to a few glomeruli not labeled by NP225-GAL4 (arrowheads). A few glomeruli express neither NP225-GAL4 nor Oamb::EGFP (asterisks). One arrow indicates a PN process. ( $B$, top row) Oamb::EGFP does not overlap with APL termini labeled by anti-GABA (example at arrows). Note the prominent GABA boutons without Oamb::EGFP at the periphery of glomeruli. (Bottom row) APL projections labeled by NP0732-GAL4. Varicosities along processes are devoid of Oamb::EGFP. (C) Oamb::EGFP does not overlap substantially with Odd neuron dendrites labeled by OK263-GAL4. Prominent varicosities are devoid of GFP (arrows). A glomerulus labeled by Oamb::EGFP does not overlap with Odd neuron dendrites (dotted line). ( $A-C$ ) Representative glomeruli labeled by Oamb::EGFP are indicated by dotted lines and arrows. (D) Antennal lobe of a larva carrying Oamb::EGFP, NP225-GAL4, and UAS-RFP labeled with chick polyclonal anti-GFP, anti-DsRed, and anti-Dlg. Oamb::EGFP is detected in PN cell bodies (arrows), and cell bodies not labeled by NP225-GAL4 (arrowheads). Notice the weak diffuse labeling of Oamb:: EGFP in the AL. Scale bar, $10 \mu \mathrm{m}$.

activation on the unconditioned stimulus pathway during differential conditioning using the similar odor pair under amber light, we tested for an effect of amber light applied during testing, after conditioning as normal in blue light. Similar to activation during conditioning (Fig. 9B), CsChrimson activation during testing also abolished odor discrimination learning that was seen under blue light (Fig. 9C). Underlying odor preferences between the similar odor pair were also not affected by OA neuron activation, nor by the amber light used to activate them (Fig. 9D).

\section{Discussion}

OA neurons target extrinsic neurons within the calyx circuitry

Two OA neurons originating in the SEZ, sVUMmd1 and sVUMmx1, innervate the same brain neuropiles, with postsynaptic processes in the SEZ and presynaptic processes in the antennal lobe and $\mathrm{MB}$ calyces (Fig. 2). Using GRASP, we found contacts of sVUM1 presynaptic terminals with KCs, PNs, Odd, and APL neurons in the calyx. Most of these overlap with OA boutons, suggesting that sVUM1 terminals are mainly presynaptic, acting on presynaptic regions of PNs and the APL, and dendritic regions of KCs and the Odd neurons. Most third-instar KCs have about six dendritic processes ending in a claw around a calyx glomerulus (Masuda-Nakagawa et al. 2005), and our GRASP counts of sVUM1-KC contacts overlapping with $\mathrm{OA}$ are far fewer than the termini that would be needed to synapse onto the 250-300-KCs present in third-instar larvae (Pauls et al. 2010). Eichler et al. (2017) also find inputs of either sVUM1 neuron (which they call OAN-a1 and OAN-a2) into $<10 \%-15 \%$ of KCs in first-instar larvae. Therefore, context-dependent signaling by $\mathrm{OA}$ in the calyx must principally affect $\mathrm{MB}$ activity via other $\mathrm{MB}$ neurons, rather than by direct action on KC dendrites, although the sVUM1 neurons may act directly on a subset of KCs.

Connectomic analysis of a 6-h firstinstar larva shows that the sVUM1 neurons, OAN-a1 and OAN-a2 neurons (Eichler et al. 2017), with only 28 presynaptic termini marked in a left brain and 39 in a right brain (Fig. 5), have a qualitatively similar but less extensive calyx innervation pattern than we observe in third instar, with around 89 OA-positive boutons per calyx, and even more active zones, assuming multiple active zones per bouton. Neuromodulatory inputs might develop later in development, as they might need experience-dependent activity to develop, and when behavioral demands increase at a more mature state. Processes of sVUM1 neurons throughout the calyx were more elaborated in the third instar (Fig. 1) compared with the sparse branching of sVUM1 neurons in the first-instar larval connectome image (Fig. 5). Consistent with 
A
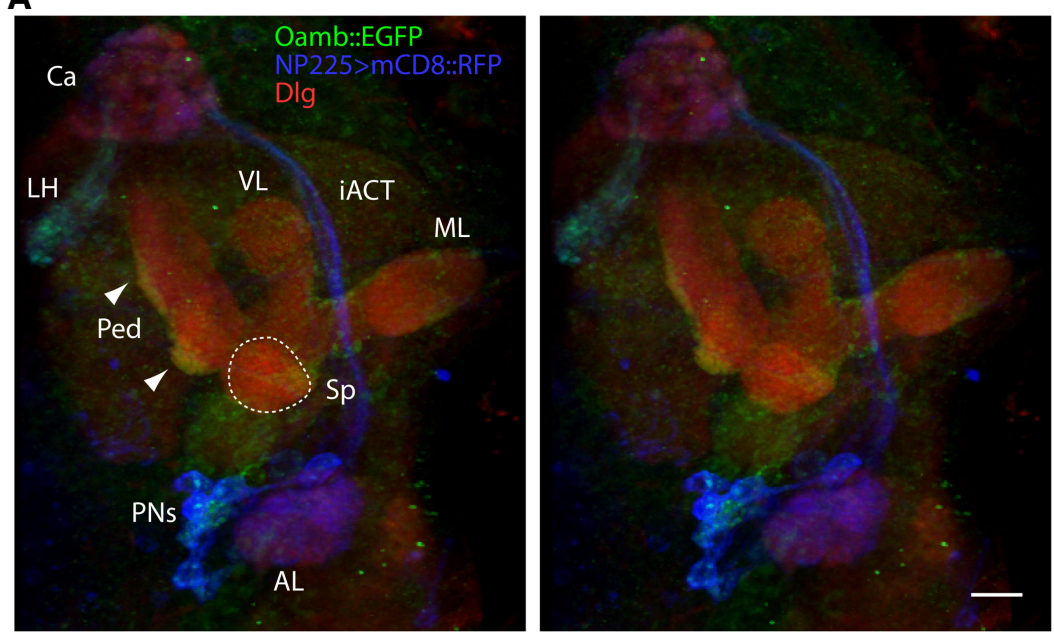

B
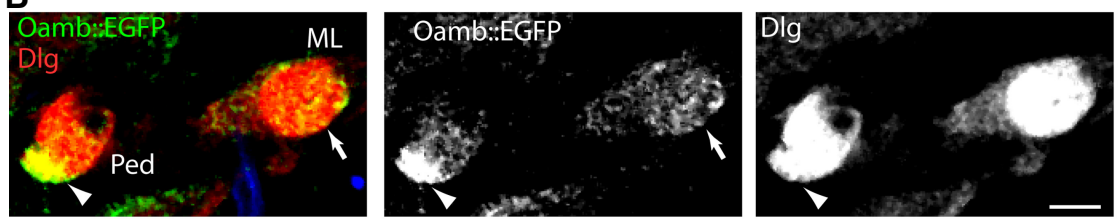

C
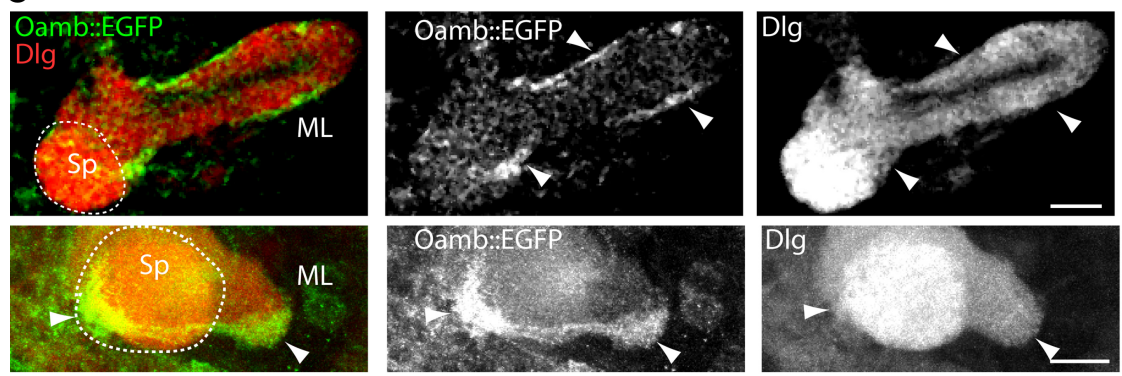

D
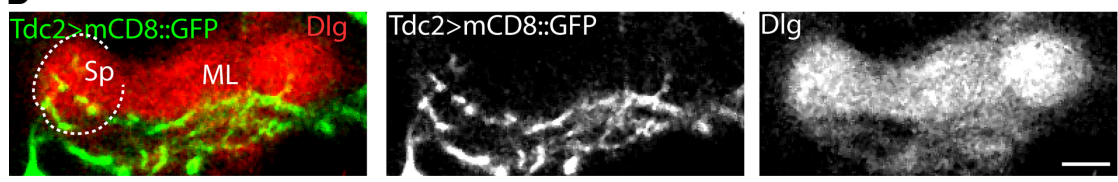

Figure 7. Oamb-EGFP localization in MB pedunculus and lobes. $(A) 3 D$ stereo pair of images of frontal views of a third-instar larval PN pathway in a single brain hemisphere, expressing Oamb::EGFP, NP225-GAL4 and UAS-RFP labeled with chick anti-GFP, anti-DsRed, and anti-Dlg. PNs with cell bodies lateral to the AL project to the MB calyx and the LH (lateral horn) via the iACT (inner antennocerebral tract). Oamb::EGFP was detected at the lateral horn (LH) and calyx, lateral pedunculus (arrowheads), and medial lobes (ML). (B) Confocal section showing Oamb::EGFP localization in lateral pedunculus (arrowhead) and medial lobe (arrow). (C, top row) Confocal section showing Oamb::EGFP in the medial lobe (ML) and in the heel of the MB. (Bottom row) Higher-magnification section of Oamb::GFP labeling at the spur (Sp) and medial lobe. $(D)$ Section through the MB spur and medial lobe in third-instar larva carrying Tdc2-GAL4 and UAS-mCD8::GFP. Notice the GFP-expressing processes at the ventral side of the medial lobe and the spur. The spur region is indicated by dashed lines in $A, C$, and $D$. Scale bars, $10 \mu \mathrm{m}$. rons ramify throughout the calyx and receive input from PNs generally, potentially forming a channel for nonselective odor processing that is parallel to the main $\mathrm{MB}$ odor-specific processing through KCs. sVUM1 neurons could potentially change the Odd neuron gain or tuning properties, to signal changes in behavioral state that guide odor-driven choice behaviors, for example during chemotactic behavior, in which Odd neurons are implicated (Slater et al. 2015).

The APL mediates a negative feedback loop from $\mathrm{KC}$ outputs in the $\mathrm{MB}$ lobes to KC inputs in the calyx, thus potentially both limiting the duration of $\mathrm{KC}$ activity and improving their odor discrimination (Lin et al. 2014; MasudaNakagawa et al. 2014). sVUM1 synapses onto the APL in the calyx could therefore potentially modulate this feedback loop. This could increase signal-to-noise ratio, in a context-dependent manner, by sharpening odor representations in the calyx via APL inhibitory feedback, similar to the "gain control" mechanism with enhancement of behaviorally relevant responses and suppression of nonrelevant ones in monkey visual system (Treue and Martínez Trujillo 1999; Gilbert and Li 2013). On the other hand, at extremes, this would also decrease the sensitivity to input, and hence decrease learning. Inhibition of the APL enhances learning, by increasing the sensitivity to input (Liu and Davis 2009).

In addition, since we observed some GRASP signals adjacent to GABA termini (Fig. 3E), APL feedback could also inhibit OA release from sVUM1 termini, further increasing the complexity of interactions between OA innervation and the KC/APL negative feedback loop. NA regulation of inhibitory neurons is also a feature of the mammalian olfactory circuitry. In the olfactory bulb, disinhibition of mitral cell (equivalent to PN) activity by NA regulation of inhibitory granule cells has been proposed (Nai et al. 2009). In mammalian PCx, feedforward and feedback inhibition are postulated to enhance cortical representation of strong inputs (Stokes and Isaacson 2010), and the PCx receives extensive NA innervation from the LC, although its role in modulating inhibition has not been investigated. our findings, Eichler et al. (2017) also report presynaptic contacts of sVUM1 neurons with Odd neuron dendrites, and some synapses of sVUM1 neurons with KCs, but not with most KCs; they do not comment on synapses with PNs or the APL.

\section{Roles of APL and Odd neurons in calyx activity}

sVUM1 presynaptic termini make many contacts with both the APL and Odd neurons in third-instar larvae (Figs. 3, 4). Odd neu-

\section{PNs as potential targets of OA modulation}

GRASP analyses suggest that PNs are postsynaptic to the sVUM1 neurons (Fig. 3). Indeed, an Oamb::EGFP exon-trap fusion is localized on PN presynaptic terminals, albeit more widely than GRASP puncta (Fig. 6). Similarly, the honeybee Oamb ortholog AmOA1 is found widely in the calyx (Sinakevitch et al. 2011), although these authors do not distinguish between PN terminals or KC dendrites. Much aminergic neurotransmission acts via extrasynaptic 


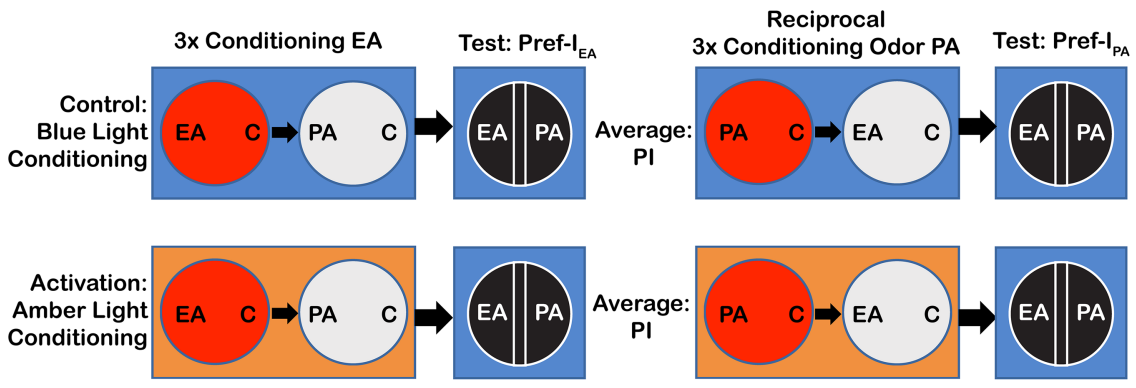

Figure 8. Behavioral discrimination assay and optogenetics. Larvae were conditioned for three cycles of an agarose fructose plate (red), carrying a container with one odor (here ethyl acetate [EA]) and a control container with mineral oil (C), followed by an agarose plate lacking fructose (light gray), but carrying a container with a different odor (here pentyl acetate [PA]) and a control container with mineral oil. Larvae were then tested by being placed on an oblong area in the middle of an agarose plate, with a choice of EA or PA, and a black background to provide contrast for counting larvae, and a conditioned preference index for EA (Pref-I $\mathrm{I}_{\mathrm{EA}}$ ) was measured. A different group of larvae were conditioned and tested with reciprocal odor pairing. Learning was measured as a performance index $(\mathrm{PI})$ averaged from Pref-I $\mathrm{EA}_{\mathrm{E}}$ and Pref-I PA. (Top row) Control experiments were carried out in dim blue light. Optogenetic activation of CsChrimson was accomplished by amber light during the conditioning phases.

receptors (Bentley et al. 2016), and this may be the case for Oamb in PN terminals. sVUM1 neurons have dense core vesicles (DCV), and these might release peptides together with OA (Tao et al. 2019). However, it is known that OA is packed into vesicles by DVMAT-A (Greer et al. 2005) in Drosophila, and although we can not exclude the possibility of volume transmission rather than classical synapses as an extra mechanism of release, this has not been documented for OA.

Oamb is a GPCR that signals apparently through Gq, to release $\mathrm{Ca}^{2+}$ from intracellular stores (Balfanz et al. 2005; Morita et al. 2006); it may also elevate cAMP (Han et al. 1998), although this effect appears smaller (Balfanz et al. 2005). In adult Drosophila, Tomchik and Davis (2009) found that bath application of OA increased cAMP responses in PN axons. These results suggest that OA can excite PN neuron terminals via cAMP, and thus facilitate synaptic transmission. In agreement with this, presynaptic facilitation was observed in Aplysia sensory neurons through the cAMP/PKa pathway after exogenous expression of the OA receptor, Ap oa 1 (Chang et al. 2000).

Since we also observe GRASP signals between sVUM1 neurons and a minority of KCs, a cAMP-mediated mechanism in KCs could also facilitate synaptic transmission; elevating cAMP facilitates $\mathrm{Ca}^{2+}$ responses of $\mathrm{MB}$ neurons to stimulation by ACh (Tomchik and Davis 2009). The cAMP/PKA pathway in MB neurons can also affect the duration of excitation through a $\mathrm{K}^{+}$-channel-mediated mechanism (Aoki et al. 2008). However, we did not observe Oamb receptor expression in KC dendrites.

An alternate mechanism of OA in plasticity is that subthreshold sensory input could be gated by OA to facilitate the detection of subthreshold signals. In the mammalian olfactory bulb, LC input facilitates the detection of peri-threshold stimuli and nearthreshold rewarded odors (Jiang et al. 1996; Escanilla et al. 2012), via an increase in mitral cell excitability mediated by NA action on $\alpha 1$-adrenergic receptors (Ciombor et al. 1999; Hayar et al. 2001). Therefore, Oamb receptors in PN terminals in the calyx could potentially participate in plastic changes to facilitate the detection of behaviorally relevant sensory input in a given behavioral context.

\section{Odor discrimination learning}

We selected odorants as a dissimilar pair, EA and PA, that activate different sets of glomeruli in the AL (Kreher et al. 2008). On the other hand, odor mixtures, which we used as the basis of our sim- ilar odor pairs, often activate patterns in the olfactory centres that are a combination of single odorant response in honeybees (Joerges et al. 1997) and mice (Grossman et al. 2008). How this pattern of activity is translated into perceptual similarity is not entirely clear, but representations in the cortex do correlate with behavioral discrimination (Chapuis and Wilson 2012). Reinforced olfactory discrimination has been used in honeybees (Stopfer et al. 1997), Drosophila (Lin et al. 2014), and mammals (Linster and Cleland 2001), to test neural mechanisms of odor discrimination.

Here we observed that optogenetic activation of five OA neurons, including the VUM1 neurons, compromised discrimination of similar odors in an appetitive conditioning paradigm, either during conditioning, or during testing (Fig. 9). The anatomical organization of KCs in the calyx predicts that KCs are coincident detectors of multiple inputs; a single KC innervates about six calyx glomeruli, and therefore would fire selectively only when coincident inputs to a given KC are activated (Masuda-Nakagawa et al. 2005). This hypothesis is consistent with physiological recordings showing that KCs fire transiently with high selectivity in locust (Perez-Orive et al. 2002), and in Drosophila (Turner et al. 2008). This suggests a model in which $\mathrm{KC}$ responses would determine the selectivity to input and hence the discrimination ability of the calyx, that is, higher calyx input activity would result in low discrimination, with overlapping in odor representations by KCs, while lower input activity might improve discrimination at the expense of sensitivity. On the other hand too low input activity would make the system unable to discriminate. Our result is consistent with OA innervation affecting the selectivity of odor representations by KCs, both during formation of odor memory, and during recall. Based on the presence of OA receptors in PN terminals (Fig. 6), we hypothesize that VUM1 activation might modulate the gain of stimulus-driven PNs, increasing the magnitude and number of KCs responding, and thus making representations of similar odors by KCs overlap more, and lowering their discriminability. On the other hand, the representations of dissimilar odors might be distinct enough to be discriminable by the calyx circuit.

A role for $\mathrm{OA}$ as a reinforcer in appetitive associative learning has been shown in honeybees and flies. The honeybee VUMmx1 neuron has properties of a reinforcer; its depolarization could replace sugar reinforcement in appetitive learning (Hammer 1993), and injection of OA into the MB calyx induced memory consolidation (Hammer and Menzel 1998). On the other hand, it has been proposed that VUMmx1 learns about the value of the odor, and acts as a prediction error signal in appetitive learning (Menzel 2012). However, associative plasticity in the MBs in Drosophila is thought to reside mainly in the lobes rather than the calyx, for both appetitive (Schwaerzel et al. 2003; Schroll et al. 2006; Liu et al. 2012) and aversive learning (Aso et al. 2012, 2014). OA as a reinforcer in appetitive learning appears to act via Oamb expressed in PAM dopamine neurons that target the medial MB lobes. The NP7088-GAL4 line that includes the fly equivalent of the honeybee VUMmx1, OA-VUMa2, did not induce and is not required for appetitive learning in adult Drosophila (Burke et al. 2012). In larvae, pPAM neurons that innervate the medial lobe appear to be involved in reward learning (Rohwedder et al. 2016). We found Oamb::GFP at the tip and around the MB medial lobe (Fig. 7), suggesting this as a potential site of integration of appetitive 
A
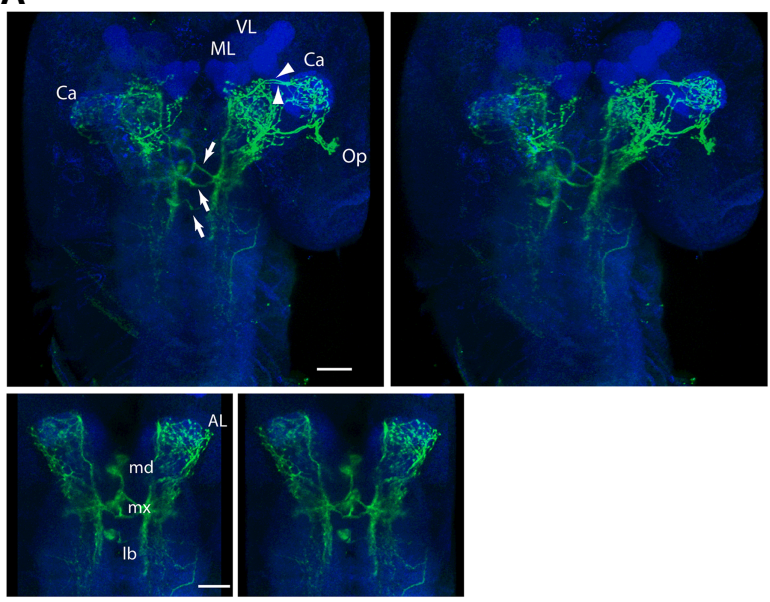

B

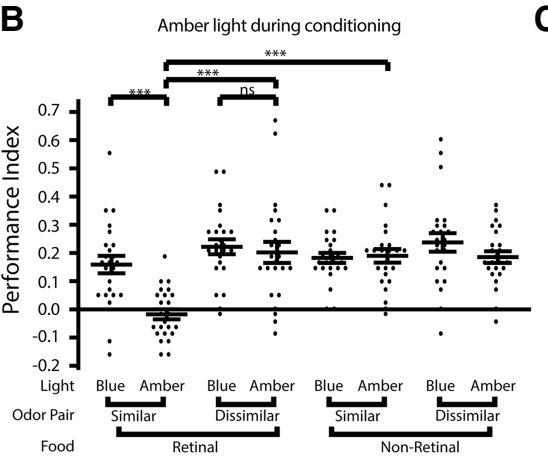

C Amber light during testing (similar odors, retinal)

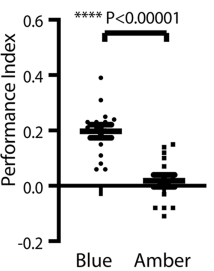

Blue Amber

Figure 9. Activation of a small subset of OA neurons including the sVUM1 neurons disrupts odor discrimination but not learning. (A) Third-instar larvae of genotype w, FRT.GAL80; Tdc2-LexA(II)/ LeXAop2-FLPL(II); GMR34A11-GAL4(III)/UAS-CsChrimson.mVenus(III), used for behavior, generated as in Figure 4A. The top panels show a pair of stereo images with CsChrimson.mVenus expressed in a subset of five sVUM neurons, including calyx-innervating sVUM1 neurons. Arrows indicate the secondary processes of the three sVUM1 clusters at the midline. The two tracts entering the calyx are indicated by arrowheads. Scale bar, $40 \mu \mathrm{m}$. The bottom row shows a close-up pair of stereo images of the vicinity of the SEZ; two cell bodies of sVUM1 md cluster, two cell bodies of sVUM1 mx cluster, and one cell body of the labial cluster are labeled. Antennal lobe (AL), calyx (Ca), optic lobe (Op), MB medial (ML), and vertical (VL) lobes act as landmarks. Scale bar, $20 \mu \mathrm{m}$. (B) Activation of the neurons labeled in $A$ by CsChrimson in the presence of retinal and amber light (applied during conditioning), abolishes odor choice learning using a similar odor pair, compared with controls exposed to blue light, lacking retinal, or tested with a dissimilar odor pair. No effect of CsChrimson activation is seen on learning using a dissimilar odor pair. Planned statistical comparisons shown are $t$-tests. $\left.{ }^{* * *}\right) P<0.0001$, (NS) $P$ $>0.6$. $n=24$. An ANOVA test of all data from two experimenters showed no significant effect of experimenter alone, or as interactions with other factors $(P>0.2)$. ANOVA tests showed no significant effect of odor alone $(P>0.03$, not significant with multiple testing), retinal alone $(P>0.4)$, or light alone $(P>0.2)$, when comparisons that would have included the retinal, amber, similar combination with the strong effect were excluded. (C) Amber light abolishes learning using a similar odor pair in the presence of retinal, if applied only during testing, after conditioning in blue light $\left(P<10^{-5}, t\right.$-test, $\left.n=15\right)$. A two-way ANOVA showed no significant difference between two experimenters $(P>0.25)$, nor any interaction between experimenter and light $(P>0.7)$. ( $D$ ) No effect of light color on naive odor preference. Larvae of the same genotype, grown on retinal-containing food as in $B$ and $C$, were tested for naive odor preferences under either blue or amber light. No effect was detected (paired $t$-test, $n=12$ ).

reinforcement for learning. Furthermore, Oamb is required in KCs for adult appetitive learning (Kim et al. 2013), suggesting some direct input of an OA-encoded appetitive signal into KCs; the localization of Oamb to $\mathrm{MB}$ lobes (Crittenden et al. 1998) is consistent with $\mathrm{OA}$ signaling on $\mathrm{KC}$ axons in the lobes rather than dendrites in the calyx. Taken together, OA action as mediating reward in associative learning might occur via unidentified inputs into dopaminergic neurons or KC lobes.

sVUM1 neurons innervate the $\mathrm{AL}$, and synapse with inhibitory interneurons (Supplemental File S1); therefore, OA can modulate the processing of olfactory signals. In honeybee, injection of $\mathrm{OA}$ in the antennal lobes impairs memory acquisition and recall but not odor discrimination (Farooqui et al. 2003). Noradrenalin in mammals has a role in olfactory memory formation by affecting the inhibitory network in the olfactory bulb (for review, see Kaba and Nakanishi 1995). Therefore, OA is likely to be involved in synaptic plasticity in the first relay of the olfactory pathway, sharpening its output. In our studies we tested odor discrimination ability, and our results favor the interpretation that $\mathrm{OA}$ acts by changing the efficacy of synaptic input to the MBs, at the calyx. A role in gating behaviorally relevant sensory input is favored by our behavioral data, and is also suggested as a role of OA in modulating the threshold response of peripheral sensory receptors and afferents in insects and NA in the CNS of mammals (Berridge and Waterhouse 2003). Our behavioral data could be interpreted to result from an increase in the levels of sensitivity, at expense of discrimination, to meet the demands of changes in behavior, signaled by OA.

\section{Perspectives}

Sensory representations are dynamically modified by higher brain signaling, according to behavioral states such as attention, expectation, and behavioral task; and LC (locus coeruleus) activation in mammals and OA activation in insects correlate with changes in behavioral states. Mammalian olfactory neuropiles are densely innervated by noradrenergic input, similar to the dense innervation of the AL and calyx by OA sVUM1 neurons in insects. The innervation of sVUM1 neurons throughout the calyx, and their potential synaptic connections to PNs, KCs, APL, and Odd neurons, mean that OA could induce a network level switch either by gating input afferent activity, and/or by interacting with the KC/APL feedback loop, and thus also affecting the output activity from the calyx - not only through KCs but also potentially via the Odd neurons. Behavioral demands would determine the balance between sensitivity and discrimination via OA; whether to escape from a predator at all cost, or the need for fine discrimination to recognize food.

\section{Materials and Methods}

\section{Genetics and molecular biology}

\section{Fly stocks}

Flies were raised on standard cornmeal medium at $25^{\circ} \mathrm{C}$ and subjected to a 12-h day/night cycle. Stocks used are listed in Table 1. 
Table 1. Drosophila stocks used

\begin{tabular}{|c|c|c|c|c|c|}
\hline Genotype & Source & Reference & RRID & Use & Figure \\
\hline NP2631-GAL4 (II) & T. Awasaki, K. Ito & $\begin{array}{l}\text { Masuda-Nakagawa } \\
\text { et al. } 2014\end{array}$ & DGGR_104266 & APL neuron & $3 A, E, 4 D$ \\
\hline NP0732-GAL4 (I) & T. Awasaki, K. Ito & $\begin{array}{l}\text { Masuda-Nakagawa } \\
\text { et al. } 2014\end{array}$ & DGGR_112307 & APL neuron & $6 \mathrm{~B}$ \\
\hline NP225-GAL4 (II) & T. Awasaki, K. Ito & $\begin{array}{l}\text { Masuda-Nakagawa } \\
\text { et al. } 2005\end{array}$ & DGGR_112095 & $\mathrm{PN}$ & $3 A, B, 6 A, D 7 A$ \\
\hline OK263-GAL4 (II) & C.J.O., L.M.M.-N. & This work & & Odd neurons & $3 A, D, 4 C, 6 C$ \\
\hline $\begin{array}{l}\text { Mef2-GAL4 (III) (also known as } \\
\text { MB247-GAL4) }\end{array}$ & BDSC 50742 & Zars et al. 2000 & & $\mathrm{KCs}$ & $3 \mathrm{~A}, \mathrm{C}$ \\
\hline GMR34A11-GAL4 (III) & BDSC 49767 & Jenett et al. 2012 & BDSC_49767 & sVUM1 neuron & $4 \mathrm{~A}, 9$ \\
\hline$T d c 2-G A L 4$ (II) & BDSC 9313 & Cole et al. 2005 & BDSC_9313 & OA neuron & $1,2,3 F, 7 D$ \\
\hline Tdc2-LexA (II) & $\begin{array}{l}\text { S. Certel, } \\
\text { S. Waddell }\end{array}$ & Burke et al. 2012 & & OA neuron & $3 \mathrm{~A}, \mathrm{C}, 4$ \\
\hline Tdc2-LexA (III) & $\begin{array}{l}\text { S. Certel, } \\
\text { S. Waddell }\end{array}$ & Burke et al. 2012 & & OA neuron & $3 A, B, D, E$ \\
\hline GMR34A11-LeXA (II) & BDSC 52755 & Jenett et al. 2012 & BDSC_52755 & sVUM1 & $4 \mathrm{~A}, 9$ \\
\hline NP225-GAL4 (II); Tdc2-LexA(III) & & This work & & GRASP & $3 \mathrm{~A}, \mathrm{~B}$ \\
\hline OK263-GAL4; Tdc2-LexA(III) & & This work & & GRASP & $3 A, D, 4 C$ \\
\hline NP2631-GAL4; Tdc2-LexA(III) & & This work & & GRASP & $3 \mathrm{~A}, \mathrm{E}, 4 \mathrm{D}$ \\
\hline Tdc2-LexA (II); Mef2-GAL4 & & This work & & GRASP & $3 \mathrm{~A}, \mathrm{C}$ \\
\hline Tdc2-LexA (II); GMR34A11-GAL4 (III) & & This work & & sVUM1 intersection & $4 \mathrm{~A}, 9$ \\
\hline UAS-mCD8::GFP (III) & BDSC 5130 & Lee and Luo 1999 & BDSC_5130 & mCD8::GFP reporter & $\begin{array}{l}2 \mathrm{D}, 3 \mathrm{~F}, 6 \mathrm{~B}, \mathrm{C} \\
7 \mathrm{D}\end{array}$ \\
\hline 10XUAS-IVS-mCD8::RFP (attP40) (II) & BDSC 32219 & Pfeiffer et al. 2010 & BDSC_32219 & mCD8::RFP reporter & $6,7 \mathrm{~A}$ \\
\hline 13XLexAOp-mCD8::GFP (III) & BDSC 32203 & Pfeiffer et al. 2010 & BDSC_32203 & $\begin{array}{l}\text { mCD8::GFP } \\
\text { reporter, to verify } \\
\text { LexA stocks }\end{array}$ & \\
\hline UAS-CD4::tdTomato (II) & BDSC 35841 & Han et al. 2011 & BDSC_35841 & Neuronal polarity & $2 \mathrm{~A}$ \\
\hline UAS-nSyb::GFP (III) & M. Ramaswami & Estes et al. 2000 & & Neuronal polarity & $2 \mathrm{~A}$ \\
\hline UAS-CD4::tdTomato (II); UAS-nSyb::GFP (III) & & This work & & Neuronal polarity & $2 \mathrm{~A}$ \\
\hline UAS-Syt::GFP UAS-DenMark::mCherry (III) & BDSC 33065 & Nicolaï et al. 2010 & BDSC_33065 & Neuronal polarity & $2 \mathrm{~B}, \mathrm{C}$ \\
\hline $\begin{array}{l}\text { 10XUAS-IVS-mCD8::RFP, } \\
\text { 13XIexAOp2-mCD8::GFP }(X)\end{array}$ & BDSC 32229 & Pfeiffer et al. 2010 & BDSC_32229 & $\begin{array}{l}\text { Double reporter, to } \\
\text { verify GAL4 LexA } \\
\text { stocks }\end{array}$ & \\
\hline UAS-CD4::spGFP1-10 & K. Scott & $\begin{array}{l}\text { Gordon and Scott } \\
2009\end{array}$ & & GRASP & 3 \\
\hline LexAop-CD4::spGFP11 & K. Scott & $\begin{array}{l}\text { Gordon and Scott } \\
2009\end{array}$ & & GRASP & 3 \\
\hline $\begin{array}{l}\text { LexAOp2-IVS > stop > spGFP1 1::CD4:: } \\
\text { HA-T2A-Brp::mCherry (attP2), } \\
\text { UAS-spGFP1-10::CD4, UAS- HRP::CD2 }\end{array}$ & C.-H. Lee & $\begin{array}{l}\text { Karuppudurai et al. } \\
2014\end{array}$ & & Single-cell GRASP & $4 B-D$ \\
\hline $\begin{array}{l}P\{h s F L P\} 12 \text { y w; +; LexAOp2-IVS > stop > } \\
\text { spGFP11::CD4::HA-T2A-Brp::mCherry } \\
\text { (attP2), UAS-spGFP1-10::CD4, UAS- HRP:: } \\
\text { CD2 }\end{array}$ & & This work & & Single-cell GRASP & $4 B-D$ \\
\hline$P\{h s F L P\} 12$ y w; CyO/Sco & $\begin{array}{l}\text { Fly Facility, } \\
\text { Department of } \\
\text { Genetics }\end{array}$ & & BDSC_1929 & Single-cell GRASP & $4 B-D$ \\
\hline $\begin{array}{l}\text { pBPhsFIp2::PEST(attP3); +; } \\
\text { HA_V5_FLAG_OLLAS (III) }\end{array}$ & M. Landgraf & Nern et al. 2015 & BDSC_64086 & $\begin{array}{l}\text { Multicolor FlpOut } \\
\quad(\text { MCFO-2) }\end{array}$ & 1 \\
\hline Tub84B(FRT-GAL80)1, w; BI/CYO; TM2/TM6B & BDSC 38879 & & BDSC_38879 & sVUM1 intersection & $4 A, 9$ \\
\hline P\{8xLexAop2-FLPL\}attP40 (II) & B. Pfeiffer, Janelia & & BDSC_55820 & sVUM1 intersection & $4 \mathrm{~A}, 9$ \\
\hline UAS-Chrimson.mVenus (III) & BDSC 55136 & Klapoetke et al. 2014 & BDSC_55136 & $\begin{array}{l}\text { Effector/reporter for } \\
\text { intersectional lines }\end{array}$ & $4 \mathrm{~A}, 9$ \\
\hline $\begin{array}{c}\text { Tub84B(FRT-GAL80)1, w; P\{8xLexAop2-FLPL }\} \\
\text { attP40(II); UAS-Chrimson.mVenus (III) }\end{array}$ & & This work & & sVUM1 intersection & $4 \mathrm{~A}, 9$ \\
\hline$y^{1} w^{*} ;+; M i\{M I C\} O a m b^{M 112417}$ & BDSC 57940 & Venken et al. 2011 & BDSC_57940 & $\begin{array}{l}\text { Progenitor of } \\
\text { Oamb::EGFP }\end{array}$ & \\
\hline $\begin{array}{l}y^{7} w^{*} ;+; \text { Mi\{PT-GFSTF.1\}Oamb }{ }^{\text {MI12417-GFSTF.1 }} \\
\quad \text { TM6C }\end{array}$ & $\begin{array}{l}\text { Fly Facility, } \\
\text { Department of } \\
\text { Genetics }\end{array}$ & This work & & Oamb::EGFP & $6,7 A, B, C$ \\
\hline UAS-mCD8::RFP; Oamb::EGFP & & This work & & $\begin{array}{l}\text { Oamb::EGFP } \\
\text { colocalization }\end{array}$ & $6,7 \mathrm{~A}$ \\
\hline Mi\{MIC\}Oct $\beta 1 R^{M 105807}$ & BDSC 42119 & Venken et al. 2011 & BDSC_42119 & $\begin{array}{l}\text { Progenitor of } \\
\text { Oct } \beta 1 R:: E G F P\end{array}$ & \\
\hline $\operatorname{Mi}\{M I C\} O c t \beta 2 R^{M / 13416}$ & BDSC 59133 & Venken et al. 2011 & BDSC_59133 & $\begin{array}{l}\text { Progenitor of } \\
\text { Oct } \beta 2 R:: E G F P\end{array}$ & \\
\hline $\operatorname{Mi}\{M I C\} O c t \beta 2 R^{M 106217}$ & BDSC 43050 & Venken et al. 2011 & BDSC_59133 & $\begin{array}{l}\text { Progenitor of } \\
\text { Oct } \beta 3 R:: E G F P\end{array}$ & \\
\hline Mi\{PT-GFSTF.2\}OCt $\beta 1 R^{M 105807-G F S T F .2}$ & BDSC 60236 & Venken et al. 2011 & BDSC_60236 & Oct $\beta 1 R:: E G F P$ & \\
\hline Mi\{PT-GFSTF.2\}Oct $\beta 2 R^{M I 13416-G F S T F .2}$ & $\begin{array}{l}\text { Fly Facility, } \\
\text { Department of } \\
\text { Genetics }\end{array}$ & This work & & Oct $\beta 2 R:: E G F P$ & \\
\hline
\end{tabular}


Table 1. Continued

\begin{tabular}{|c|c|c|c|c|c|}
\hline Genotype & Source & Reference & RRID & Use & Figure \\
\hline Mi\{PT-GFSTF.0\}Oct $\beta 3 R^{M 106217-G F S T F .0}$ & $\begin{array}{l}\text { Fly Facility, } \\
\text { Department of } \\
\text { Genetics }\end{array}$ & This work & & $\begin{array}{l}\text { Oct } \beta 3 R: \text { :EGFP line, } \\
\text { GFP intron } \\
\text { phase } 0\end{array}$ & \\
\hline Mi\{PT-GFSTF.1\}Oct $\beta 3 R^{M 106217-G F S T F .1}$ & BDSC 60245 & $\begin{array}{l}\text { Nagarkar-Jaiswal et al. } \\
2015\end{array}$ & BDSC_60245 & $\begin{array}{l}\text { Oct } \beta 3 R: \text { :EGFP line, } \\
\text { GFP intron phase } \\
1\end{array}$ & \\
\hline
\end{tabular}

Includes all genotypes used for this study, including those that do not appear in figures.

\section{Multicolor FlpOut}

Multicolor FlpOut was performed according to Nern et al. (2015). Females of genotype pBPhsFlp2::PEST(attP3); +; HA_V5_FLAG_ OLLAS ("MCFO-2") were crossed with male Tdc2-Gal4 flies. Parents were left in vials to lay eggs for 24-h intervals. After another $24 \mathrm{~h}$, larval progeny were heat shocked at $35^{\circ} \mathrm{C}-37^{\circ} \mathrm{C}$ by immersion in a heated circulated waterbath for 15-30 min, thus ensuring larvae were aged $24-48 \mathrm{~h}$ after egg laying (AEL) at the time of heat shock.

\section{GRASP}

Standard GRASP was according to Gordon and Scott (2009). A line carrying GRASP constructs UAS-CD4::spGFP1-10 and LexAop-CD4:: spGFP11, was crossed to individual LexA GAL4 lines as needed: NP225-GAL4(II); Tdc2-LexA(III), OK263-GAL4(II); Tdc2-LexA(III), NP2631-GAL4(II); Tdc2-LexA(III), or Tdc2-LexA(II); Mef2-GAL4(III) (Fig. 3), or to individual GAL4 or LexA lines as controls (Supplemental Fig. S1). Reconstituted GFP was detected using rat monoclonal anti-GFP. This did not detect either of the GRASP components GFP1-10 or GFP11, when Gal4 or LexA drivers were used alone (Supplemental Fig. S1). GRASP signals had to meet a criterion of occurring in two consecutive $0.5-\mu \mathrm{m}$ confocal sections. For singlecell GRASP (Karuppudurai et al. 2014), we generated larvae carrying P\{hSFLP\}12, appropriate GAL4 and LexA combinations, and a recombinant chromosome with insertions LexAOp2-IVS $>$ stop $>$ spGFP11::CD4::HA-T2A-Brp::mCherry (attP2), UAS-spGFP1-10:: $C D 4$, and $U A S-H R P:: C D 2$, by generating a stock carrying $P\{h s F L P\}$ 12 y w; +; LexAOp2-IVS > stop > spGFP11::CD4::HA-T2A-Brp:: mCherry (attP2), UAS-spGFP1-10::CD4, UAS-HRP::CD2, and crossing females of this stock to relevant GAL4 LexA males. To generate labeled single cells, parents were allowed to lay eggs initially for 24-h intervals, then for 6-h intervals in vials containing half the amount of food. At $0-24 \mathrm{~h}, 24-48 \mathrm{~h}$, or later at $12-18 \mathrm{~h}, 18-24$ $\mathrm{h}$, or $24-30 \mathrm{~h} \mathrm{AEL}$, progeny were heat shocked as above for 10$50 \mathrm{~min}$ at $37^{\circ} \mathrm{C}$. Progeny were incubated from RT until dissection of nontubby wandering third-instar larvae.

\section{Generation of an EGFP-tagged Oamb line}

The Mi\{MIC\}Oamb ${ }^{M I 12417}$ insertion in coding intron 3 of Oamb at 3R:20697059, (BDSC stock 57940; henceforth referred to as MI12417) was verified by PCR using primers MI12417-5F/ MiMIC-5R1 for the $5^{\prime}$ end and MI12417-3R/MiMIC-3F1 for the $3^{\prime}$ end (Table 2; Supplemental Fig. S2). Sequencing of these PCR products and alignment with the Drosophila genome sequence using BLASTN (Altschul et al. 1990; https://blast.ncbi.nlm.nih.gov) showed insertion of MiMIC at the recorded site of 3R 20697058-9 (Supplemental Figs. S3, S4). The location of the MI12417 insertion site relative to Oamb coding exons was determined by using Oamb-B sequences for BLASTN and TBLASTN queries of the Drosophila genome assembly (Supplemental Fig. S5; http://flybase.org/blast). TMHMM (Sonnhammer et al. 1998; http://www.cbs.dtu.dk/ services/TMHMM) was used to predict the amino acid coordinates of Oamb transmembrane (TM) domains (Supplemental Figs. 6, 7).

To insert an EGFP-encoding exon into the MI12417 insertion by RMCE, we chose the splice phase-1 version of the EGFP-FlAsH-StrepII-TEV-3xFlag plasmid (DGRC 1306) (Venken et al. 2011) as recommended by the Baylor Gene Disruption Project (http://flypush.imgen.bcm.tmc.edu/pscreen/rmce/rmce .php? entry=RM00888). This was coinjected with a helper phiC31-integrase plasmid (Venken et al. 2011) by the Drosophila microinjection facility (Department of Genetics, University of Cambridge). Injected embryos were left to hatch into adult flies and crossed to a $y w$ double balancer stock. RMCE events were identified by loss of the MiMIC yellow ${ }^{+}$marker in F1 progeny. Four PCR

Table 2. Primers

\begin{tabular}{|c|c|c|}
\hline Primer & Sequence & Purpose \\
\hline MiMIC-5R & СTTGAGATTAAGGTAGCTTACGC & Verifying $M i\{M I C\}$ insertion \\
\hline MiMIC-3F & TGCAGGTCGACGAATTCAAC & Verifying Mi $\{\mathrm{MIC}\}$ insertion \\
\hline MI12417-5F & CCACAATCAACGTCCTGCTC & Verifying Mi $\{M I C\}$ insertion \\
\hline MI12417-3R & GATTATCGCCACCACAGAGTC & Verifying Mi $\{M I C\}$ insertion \\
\hline MI05807-5F & TCCTTTCATTCCCGAGCACC & Verifying $\mathrm{Mi}\{\mathrm{MIC}\}$ insertion \\
\hline MI05807-3R & CTCGTTAACAATCGCTCGCC & Verifying $\mathrm{Mi}\{\mathrm{MIC}\}$ insertion \\
\hline MI13416-5F1 & CGGAGTCACTGAGTAATGGCG & Verifying Mi $\{M I C\}$ insertion \\
\hline MI13416-5F2 & ATGGCGAGTGGTATGAGCAG & Verifying $\mathrm{Mi}\{\mathrm{MIC}\}$ insertion \\
\hline MI13416-5F3 & GTGCTCTAGATGGCGAGTGG & Verifying Mi $\{M I C\}$ insertion \\
\hline MI13416-5F4 & ACCGAGGCTCATTAACACAG & Verifying Mi $\{M I C\}$ insertion \\
\hline MI13416-5F5 & GAGGCTCATTAACACAGCGC & Verifying Mi $\{M I C\}$ insertion \\
\hline MI13416-3R & GCTGCСТСАТTGAACTCCAG & Verifying $\mathrm{Mi}\{\mathrm{MIC}\}$ insertion \\
\hline MI06217-5F & GCAGGAGAACAGCGACAGTC & Verifying Mi $\{M I C\}$ insertion \\
\hline MI06217-3R & ССTGTCTCTGGAAGTAGGTCG & Verifying Mi\{MIC\} insertion \\
\hline Orientation-MiL-F (OriF) & GCGTAAGCTACCTTAATCTCAAGAAGAG & Verifying GFP swap orientation \\
\hline Orientation-MiL-R (OriR) & CGCGGCGTAATGTGATTTACTATCATAC & Verifying GFP swap orientation \\
\hline EGFPdo-Seq-F (EGFP-F) & GGATGACGGCACCTACAAGAC & Verifying GFP swap orientation \\
\hline EGFPdo-Seq-R (EGFP-R) & GTGGCTGTTGAAGTTGTACTC & Verifying GFP swap orientation \\
\hline
\end{tabular}


reactions were carried out to determine the orientation of the EGFP cassette in each recombinant Oamb::EGFP stock (Table 2) as described in Venken et al. (2011).

\section{Oct $\beta R$ EGFP fusions}

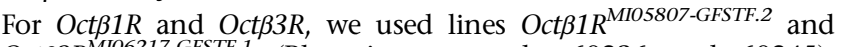
Oct $33 R^{M I O 6217-G F S T F .1}$ (Bloomington stocks 60236 and 60245), respectively, as Oct $\beta 1 R:: E G F P$ and Oct $\beta 3:: E G F P$ exon traps. For Oct $\beta 2 R$, we used Mi\{MIC\}Oct $\beta 2 R^{M I 13416}$ to generate $O c t \beta 2 R^{M I 13416-G F S T F .2}$ using a similar approach as that described above for Oamb::EGFP. We also generated a second Oct $\beta 3:: E G F P$ exon trap, Oct $\beta 3 R^{M I O 6217-G F S T F . O}$, in a different reading frame from Bloomington stock 60245 , to allow for the possibility of the EGFP exon being spliced as in transcripts $R J$ or $R K$ (frame 0 , with only $R J$ able to encode all seven TM domains), rather than $R F$ or $R G$ (frame $1)$. Positions of each insertion were confirmed by PCR and sequencing similarly to Oamb, using primers as described in Table 2.

\section{Molecular methods}

Genomic DNA was extracted from 15-30 flies (1-7 d after eclosion) and homogenized in $100 \mathrm{mM}$ Tris- $\mathrm{HCl}(\mathrm{pH} 8.5), 80 \mathrm{mM} \mathrm{NaCl}$ (Sigma 31434), 5\% sucrose (Sigma S0389), 0.5\% SDS (Sigma L4509), and 50 mM Na-EDTA (Sigma ED2SS) (pH 8.0). The homogenate was incubated with RNase A (Roche 10109142001) for $1 \mathrm{~h}$ at $37^{\circ} \mathrm{C}$ followed by Proteinase $\mathrm{K}$ (Roche 03115887001 ) for $1 \mathrm{~h}$ at $50^{\circ} \mathrm{C}$, and purified with phenol-chloroform (Sigma 77617) and chloroform (Sigma C2432). DNA was precipitated with 0.6 vol of isopropanol (Sigma 59304) and washed with 75\% ethanol (Sigma E7023), dried overnight at room temperature and resuspended in 10 mM Tris-HCl (pH 8.0) (Sigma T6066).

PCR reactions $(20 \mu \mathrm{L})$ contained $0.4 \mu \mathrm{L}$ or $1 \mu \mathrm{L}$ of genomic DNA, $1 \mu \mathrm{L}$ of each $10 \mu \mathrm{M}$ primer (Sigma), $2 \mu \mathrm{L}$ of $10 \times$ PCR buffer (Qiagen 203203), $0.4 \mu \mathrm{L}$ of $10 \mu \mathrm{M}$ dNTP mix (Roche 11581295001), $0.08 \mu \mathrm{L}$ of $5 \mathrm{U} / \mu \mathrm{L}$ HotStarTaq DNA polymerase (Qiagen 203203), and $15.1 \mu \mathrm{L}$ or $14.5 \mu \mathrm{L}$ milliQ water. PCR cycling in a G-Storm Thermal Cycler (GS4) was $15 \mathrm{~min}$ at $95^{\circ} \mathrm{C} ; 40$ cycles of denaturation for $30 \mathrm{sec}$ at $94^{\circ} \mathrm{C}$, annealing for $30 \mathrm{sec}$ at $60^{\circ} \mathrm{C}$, and elongation for $1 \mathrm{~min}$ at $72^{\circ} \mathrm{C}$; and a final elongation step for 10 min at $72^{\circ} \mathrm{C}$. PCR products were loaded with $6 \times$ DNA gel-loading dye (Thermo Fisher R0611) on a 1\% agarose gel (LifeTech 16500500; 1× TBE buffer, LifeTech 16500500) with GelRed (Biotium 41003-T) for gel electrophoresis. A 100-bp DNA ladder was used as a marker (LifeTech 15628019). PCR products were purified using the Qiaquick PCR purification iit (Qiagen, 28104), and sequenced at the Department of Biochemistry Sequencing Facility (University of Cambridge).

\section{Immunohistochemistry and confocal imaging}

Third-instar wandering larval brains (144-176 h AEL) were dissected in cold PBS (Sigma P4417), fixed in 4\% formaldehyde (Polysciences 18814)/PEM buffer (0.1 M PIPES [Sigma P1851], 2 mM EGTA [Sigma E3889], $\left.1 \mathrm{mM} \mathrm{MgSO}_{4}, \mathrm{NaOH}\right)$ for $2 \mathrm{~h}$ at $4^{\circ} \mathrm{C}$, washed three times for $10 \mathrm{~min}$ (or four times for $15 \mathrm{~min}$ ) in $0.3 \%$ Triton-X (Sigma T8787) in PBS (PBT), and incubated in 10\% NGS (normal goat serum; Vector Laboratories S-1000) in 0.3\% PBT for $1 \mathrm{~h}$ at room temperature. Brains were incubated in primary antibody in $10 \%$ NGS- $0.3 \%$ PBT for $2-3 \mathrm{~d}$ at $4^{\circ} \mathrm{C}$ on a minidisk rotor (Biocraft BC-710), washed three times for 15 min with 0.3\% PBT, and further incubated in secondary antibody in 10\% NGS for 2-3 $\mathrm{d}$ at $4^{\circ} \mathrm{C}$ again on the minidisk rotor. Brains were finally washed once for $15 \mathrm{~min}$ with PBT, followed by three times for $10 \mathrm{~min}$ with PBS, and left in 50\% glycerol/PBS for at least one night at $4^{\circ}$ $\mathrm{C}$ prior to imaging.

Primary and secondary antibodies are listed in Table 3 . Brains were incubated in primary antibody for two to three nights at $4^{\circ} \mathrm{C}$, washed three times in PBT for 15-min, and incubated in secondary antibody for two to three more nights. To reduce background with the polyclonal chicken anti-GFP (Abcam Ab13970), it was preincubated with MI12417 larval brains, which do not express GFP. Fifty MI12417 larval brains were incubated in 1:20 chicken anti-GFP in
$10 \%$ NGS in $0.3 \%$ PBT overnight at $4^{\circ} \mathrm{C}$. A further 50 MI12417 larval brains were added and further incubated over two nights at $4^{\circ} \mathrm{C}$. Mounting and orientation of brains for image acquisition was as described in the Supplemental Material in Masuda-Nakagawa et al. (2009). Imaging was carried out using a Zeiss LSM710 Confocal Microscope with a $40 \times$ NA1.3 oil objective. Images were processed using ImageJ software (https://imagej.nih.gov/ij/ download.html).

\section{Behavioral assay}

\section{Larval culture}

Males of genotype $w$; Tdc2-LexA; GMR34A11-GAL4/TM6B were crossed to females of genotype Tub84B(FRT-GAL80)1, w; LexAop-FLP; UAS-Chrimson.mVenus/TM6B to generate F1 larvae in which UAS-Chrimson.mVenus could be expressed only in cells expressing both Tdc2-LexA and GMR34A11-GAL4, in which LexA-dependent FLP expression had removed the GAL4 inhibitor GAL80. Larvae were allowed to develop in food vials containing $200 \mu \mathrm{M}$ all-trans-retinal (Sigma R2500), in the dark at 21 ${ }^{\circ}$. For both the retinal and nonretinal food vials, transfer of adults into new vials was performed both in the morning and in the evening, to then collect them after 108-120 $\mathrm{h}$ in the case of nonretinal vials at $25^{\circ} \mathrm{C}$, and after $132-144 \mathrm{~h}$ for those kept in retinal vials at $23^{\circ} \mathrm{C}$. Reagents for this and other behavioral work are listed in Table 4.

\section{Behavioral arena}

Petri dishes $(8.5-\mathrm{cm})$ containing agarose were prepared the day before use, using $100 \mathrm{~mL}$ of distilled water with $0.9 \%$ agarose (Sigma A9539). Fructose Petri dishes were prepared similarly, but containing 35\% fructose (Sigma 47740). Petri dishes had perforated lids to facilitate creation of odorant gradients within the dish, generated by sucking air away using a benchtop fume extractor (Sentry Air Systems SS-200-WSL) at the back of the assay platform. Odorants were diluted in paraffin oil (Sigma-Aldrich 76235), and 10- $\mu \mathrm{L}$ aliquots were pipetted with a cotton filled tip, immediately before conditioning or test, into custom-built Teflon containers with pierced lids (seven holes), made in the Physiology Department workshop in the University of Cambridge, based on samples kindly provided by B. Gerber.

\section{Light apparatus}

Our optogenetics apparatus was constructed as described by de Vries and Clandinin (2013) for activation of ChR. We modified it to shine amber light to activate CsChrimson. A BK Precision 1698 model DC power pack was connected to a pulse generator, driving four sets of amber light LEDs (591 nm), Luxeon star Amber LED on Tri-Star Base, $330 \mathrm{~lm}$ at $350 \mathrm{~mA}$ (SP-03-A5). The irradiance on the platform was $0.06 \mu \mathrm{W} / \mathrm{mm}^{2}$ on average $(24 \mu \mathrm{W}$ on a $20 \times 20$-mm sensor) on the 8.5 -cm plate. The pulse generator was custom-built by the Psychology Department workshop of the University of Cambridge, to deliver 10 -msec pulses at $10 \mathrm{~Hz}$ for $30 \mathrm{sec}$, followed by $30 \mathrm{sec}$ without pulses. This cycle was repeated five times, making a conditioning step of $5 \mathrm{~min}$ in total. The power supply was run at $17-\mathrm{mV}$ constant voltage. This pulse frequency and width were chosen to replicate the activity of the only recorded sVUM1 neuron, the honeybee sVUMmx1, when activated by a sucrose reward (Hammer 1993). Reagents are listed in Table 4.

\section{Behavior conditioning}

Third-instar larvae were collected from vials using a stainless steel SANPO $355 \mu \mathrm{m} / \mathrm{m}$ and washed with tap water. Larvae were washed twice by transferring through a drop of tap water, and then placed on the conditioning agarose plate (35\% fructose) with the help of a paint brush.

One conditioning cycle consisted of placing larvae in a fructose dish exposed to the odor to be conditioned with for $5 \mathrm{~min}$, and then washing in two drops of water to clean them of fructose, before transferring to an agarose dish, where larvae were exposed to 
Table 3. Antibodies

\begin{tabular}{|c|c|c|c|c|c|}
\hline & Host & Source & RRID & Dilution & Experiment or figures \\
\hline \multicolumn{6}{|l|}{ Antibody } \\
\hline Anti-GFP & Rat, monoclonal & $\begin{array}{l}\text { Nacalai } 440426 \\
\quad \text { (clone GF090R) }\end{array}$ & $A B \_2314545$ & $1: 1000$ & GRASP (3B-E) UAS-CD8::GFP \\
\hline Anti-GFP & Chicken, polyclonal & Abcam Ab13970 & AB_300798 & 1:1000/1:2000 & Oamb::EGFP $(6,7)$ \\
\hline Anti-GFP & Rabbit, polyclonal & Invitrogen A11122 & AB_221569 & $1: 1000 / 1: 2000$ & \\
\hline Anti-GFP & Rabbit, polyclonal & Abcam Ab290 & AB_303395 & $1: 800$ & \\
\hline Anti-DsRed & Rabbit, polyclonal & Clontech 632496 & $A B \_10013483$ & $1: 1000$ & $\begin{array}{l}\text { UAS-tdTom (2A), UAS-DenMark }(2 \mathrm{~B}, \mathrm{C}) \text {, Brp:: } \\
\text { mCherry }(4 \mathrm{~B}-\mathrm{D}) \text { UAS-RFP }(6,7)\end{array}$ \\
\hline Anti-GABA & Rabbit, polyclonal & Sigma A2052 & $A B \_477652$ & $1: 1000$ & $3 \mathrm{E}, \mathrm{F}, 6 \mathrm{~B}$ \\
\hline Anti-OA & Rabbit, polyclonal & MoBiTec $1003 \mathrm{GE}$ & AB_2314999 & $1: 1000$ & $3 \mathrm{~B}-\mathrm{E}$ \\
\hline Anti-Dlg & Mouse, monoclonal & DSHB 4F3 & AB_528203 & $1: 200$ & $2-4,6,7,9$ \\
\hline Anti-FLAG & Mouse, monoclonal & Sigma F1804 & AB_262044 & $1: 4000$ & MCFO \\
\hline Anti-HA & Rat, monoclonal & Roche $3 \mathrm{~F} 10$ & $\left.A B \_2314622\right)$ & $1: 1000$ & MCFO $(1 \mathrm{~A}, \mathrm{~B})$ \\
\hline Anti-V5 & Chicken, polyclonal & Abcam Ab1993 & $A B \_302743$ & $1: 1000$ & MCFO $(1 \mathrm{~A}, \mathrm{~B})$ \\
\hline \multicolumn{6}{|l|}{ Secondary antibody } \\
\hline Anti-rat Alexa 488 & Goat, polyclonal & Invitrogen A11006 & AB_2534074 & $1: 200$ & \\
\hline Anti-rat Alexa 594 & Goat, polyclonal & Invitrogen A11007 & $A B \quad 10561522$ & $1: 200$ & \\
\hline $\begin{array}{l}\text { Anti-chicken } \\
\text { Alexa } 488\end{array}$ & Goat, polyclonal & Invitrogen A1 1039 & $A B \_142924$ & $1: 200$ & \\
\hline $\begin{array}{l}\text { Anti-rabbit Alexa } \\
488\end{array}$ & Goat, polyclonal & Invitrogen A11034 & $A B \_2576217$ & $1: 200$ & \\
\hline $\begin{array}{l}\text { Anti-rabbit Alexa } \\
568\end{array}$ & Goat, polyclonal & Invitrogen A11036 & AB_10563566 & $1: 200$ & \\
\hline Anti-mouse Alexa & Goat, polyclonal & Invitrogen A21236 & AB_141725 & $1: 200$ & \\
\hline $\begin{array}{l}\text { Anti-rabbit Alexa } \\
647\end{array}$ & Goat, polyclonal & Invitrogen A21245 & $A B \_2535813$ & $1: 200$ & \\
\hline $\begin{array}{l}\text { Anti-chicken } \\
\text { Alexa } 568\end{array}$ & Goat, polyclonal & Invitrogen A11041 & $\mathrm{AB} \_2534098$ & $1: 200$ & \\
\hline
\end{tabular}

the other odor of the pair for 5 min without the reinforcer. This cycle was repeated three times. For experiments involving activation of OA neurons, the three conditioning cycles with reinforcer present and the three nonreinforced cycles were carried out under pulses of amber light (Fig. 9). For controls without activation of CsChrimson, conditioning was performed as with amber light but under dim blue light, using an aquarium lamp, covered with paper to decrease its intensity.

Containers were placed at $1 \mathrm{~cm}$ from the side of the dish (Fig. 8 ). One container was filled with odor while the one on the opposite side contained mineral oil. One experimenter (ADM) placed containers consistently at the same position throughout conditioning cycles; the other (MM) alternated oil and odor containers between sides for each 5 min of the three cycles, to avoid any inadvertent effects of illumination.

\section{Odor dilutions}

Our choice of odor was based on the cluster analysis of Kreher et al. (2008). We measured the response index (RI) of Canton-S (CS) wild-type larvae to diverse odorants of the Kreher odor panel at different intensities, aiming to reach an RI of $>0.5$, according to the widely used protocol of Monte et al. (1989), Rodrigues and Siddiqi (1978), and Kreher et al. (2008). RI was defined as RI=(S

Table 4. Other reagents

\begin{tabular}{lll}
\hline Reagent & \multicolumn{1}{c}{ Source } & Experiment or figures \\
\hline Paraffin oil & Sigma-Aldrich 76235 & Behavior \\
Pentyl acetate & Sigma-Aldrich 109584 & Behavior \\
Ethyl acetate & Sigma-Aldrich 319902 & Behavior \\
Ethanol & Sigma-Aldrich 32221 & Behavior \\
All-trans-retinal (ATR) & Sigma-Aldrich R2500 & Behavior \\
D-(-)-fructose & Sigma-Aldrich 47740 & Behavior \\
Agarose & Sigma-Aldrich A9539 & Behavior \\
\hline
\end{tabular}

$-C) /(S+C)$, where $S$ is the number of larvae on the odor side, and $\mathrm{C}$ is the number of larvae on the diluent side, after $5 \mathrm{~min}$.

We selected ethylacetate (EA; Sigma-Aldrich 319902) at $1: 2000$ dilution, which gave $\mathrm{RI}=0.57 \pm 0.04$ (mean $\pm \mathrm{SEM}, n=12$ ), in CS third-instar larvae. To establish a dissimilar odor pair, we selected pentyl acetate (PA; also known as amyl acetate or n-amyl acetate; Sigma-Aldrich 109584). EA and PA are homologous esters that differ by a length of three carbons. Since the RI for EA is higher than PA (Cobb and Dannet 1994), we used odor balancing to determine the dilution of PA that would balance EA, that is, a preference index (Pref-I) of around 0 given a choice between the two odors, first using CS wild-type larvae (Supplemental Methods in the Supplemental Material), and subsequently with larvae of the genotype used for learning and discrimination behavior, w, FRT.GAL80; Tdc2-LexA/LexAop2-FLPL; GMR34A11-GAL4 / UAS-CsChrimson. $m$ Venus,. Pref-I was calculated as (number of larvae in EA) - (number of larvae in PA)/(total number of larvae) (Scherer et al. 2003). A negative Pref-I means preference toward PA. Dilutions of EA at 1:2000 and PA at 1:500 gave a Pref-I of close to 0 , and these were used as dissimilar odors in conditioning experiments.

\section{Testing}

Larvae were tested by placing them on an agarose plate carrying a container with EA (1:2000) on one side, and a container with PA (1:500) on the opposite side (dissimilar odors), or a container with EA:PA 4:1 and one with EA:PA 1:4 (similar odors; mixes were made using the same dilutions as in the dissimilar odor pair). Testing was performed under dim blue light, as used during conditioning, for $5 \mathrm{~min}$. Larvae were counted on the side of the conditioned odor, the unconditioned odor, and in the neutral zone in the middle. A single performance index (PI) (Selcho et al. 2009) was calculated as $\mathrm{PI}=\left[\mathrm{N}_{\text {conditioned (A+) }}-\mathrm{N}_{\text {unconditionsed (B) }}\right] /$ $N_{\text {total }}$, where $\mathrm{N}_{\text {conditioned (A+) }}$ is the number of larvae on the side of the conditioned odor, $\mathrm{N}_{\text {unconditioned (B) }}$ is the number of larvae on the side of the unconditioned odor, and $\mathrm{N}_{\text {Total }}$ is the number of larvae on the side of conditioned $\mathrm{A}+$ odor, unconditioned odor $\mathrm{B}$, and middle zone. 
Since we performed a reciprocal conditioning run, to avoid nonassociative effects, a different sample of larvae were conditioned in parallel, with the previously unconditioned odor. An average performance index (PI) was calculated from the two groups of larvae $(\mathrm{A}+/ \mathrm{B}$ and $\mathrm{A} / \mathrm{B}+)$ conditioned reciprocally, using the formula $\mathrm{PI}=(\mathrm{PI}$ odor $\mathrm{A}+\mathrm{B}-\mathrm{PI}$ odor $\mathrm{A} / \mathrm{B}+) / 2$.

To test the effect of amber light during testing, the same procedure of differential conditioning with similar odors, and larvae grown in retinal-supplemented food, was performed by conditioning in blue light, and then applying either amber or blue light during testing.

\section{Controls for the effect of light on similar odor responses}

To test for any bias of larval behavior caused by amber light alone, larvae of the experimental genotype were exposed to light, in similar light conditions as in the conditioning trainings, but without fructose, and tested for their odor preferences. Thirty larvae grown in retinal food were exposed to the pair of similar odors on opposite sides of the dish, for $5 \mathrm{~min}$, under either blue light or amber light, and their preference index calculated. Containers were swapped in order to exclude bias on illumination. Trials with dissimilar odors were also included.

\section{Statistical analysis}

Single planned comparisons were performed using $t$-tests in Microsoft Excel. A four-factor ANOVA using SPSS software was used to test whether performance index was affected by food type (retinal vs. nonretinal), light (blue vs. amber), odor pairs (similar pair vs. dissimilar pair), or experimenter (either of two). Effects of experimenter on learning scores were tested using two-way ANOVA tests in GraphPad Prism 8.0 and found to be nonsignificant $(P>0.2)$. Planned comparisons between the effects of retinal/nonretinal, amber/blue light, and similar/dissimilar odors were also confirmed in GraphPad Prism using Welch's $t$-test (not assuming equal SD) and by a nonparametric Mann-Whitney test. All distributions are expressed as mean \pm standard error of the mean throughout.

Raw data and analyses files underpinning this article are available at https://doi.org/10.17863/CAM.60610.

\section{Acknowledgments}

We thank B. Gerber for odor containers; A. Cardona for access and training on CATMAID; T. Awasaki, S. Certel, K. Ito, M Landgraf, T. Lee, C.H.-Lee, B Pfeiffer, M. Ramaswami, K. Scott, J. Truman, and the Bloomington Drosophila Stock Center (BDSC) for numerous fly stocks; the Cambridge Genetics Department Fly Facility for stocks and microinjections; and the Developmental Studies Hybridoma Bank (DSHB), University of Iowa, for antibodies. We thank M. Morgan for help in building optogenetic illumination apparatus. J.Y.H.W. was supported by a Medical Research Council Studentship, and M.M. was supported by a UK Genetics Society "Genes \& Development" summer scholarship and an award from the Bedford Fund, King's College Cambridge. T.B. was funded by a Biotechnology and Biological Sciences Research Council (BBSRC) Doctoral Training Program summer placement grant. This work was supported by BBSRC grants BB/I022651/1 and BB/ N007948/1, and an Isaac Newton Trust award to L.M.M.-N. and C.J.O.

Author contributions: L.M.M.-N. and C.J.O. designed the experiments. J.Y.H.W., B.A.W., T.B., M.M., A.D.M., L.M.M.-N., and S.W. Z. performed the experiments. L.M.M.-N., B.A.W., J.Y.H.W., C.J.O., M.M., and A.D.M. analyzed the data. L.M.M.-N. drafted and wrote the manuscript.

\section{References}

Altschul SF, Gish W, Miller W, Myers EW, Lipman DJ. 1990. Basic local alignment search tool. J Mol Biol 215: 403-410. doi:10.1016/ S0022-2836(05)80360-2
Aoki K, Kosakai K, Yoshino M. 2008. Monoaminergic modulation of the $\mathrm{Na}^{+}$-activated $\mathrm{K}^{+}$channel in kenyon cells isolated from the mushroom body of the cricket (Gryllus bimaculatus) brain. J Neurophysiol 100: 12111222. doi:10.1152/jn.90459.2008

Aso Y, Herb A, Ogueta M, Siwanowicz I, Templier T, Friedrich AB, Ito K, Scholz H, Tanimoto H. 2012. Three dopamine pathways induce aversive odor memories with different stability. PLoS Genet 8: e1002768. doi:10 .1371/journal.pgen.1002768

Aso Y, Sitaraman D, Ichinose T, Kaun KR, Vogt K, Belliart-Guérin G, Plaçais PY, Robie AA, Yamagata N, Schnaitmann C, et al. 2014. Mushroom body output neurons encode valence and guide memory-based action selection in Drosophila. Elife 3: e04580. doi:10 .7554/eLife.04580

Aston-Jones G, Cohen JD. 2005. An integrative theory of locus coeruleus-norepinephrine function: adaptive gain and optimal performance. Annu Rev Neurosci 28: 403-450. doi:10.1146/annurev .neuro.28.061604.135709

Balfanz S, Strünker T, Frings S, Baumann A. 2005. A family of octapamine receptors that specifically induce cyclic AMP production or $\mathrm{Ca}^{2+}$ release in Drosophila melanogaster. J Neurochem 93: 440-451. doi:10.1111/j .1471-4159.2005.03034.x

Bauknecht P, Jékely G. 2017. Ancient coexistence of norepinephrine, tyramine, and octopamine signaling in bilaterians. BMC Biol 15: 6 . doi:10.1186/s12915-016-0341-7

Bentley B, Branicky R, Barnes CL, Chew YL, Yemini E, Bullmore ET, Vértes PE, Schafer WR. 2016. The multilayer connectome of Caenorhabditis elegans. PLoS Comput Biol 12: e1005283. doi:10.1371/ journal.pcbi.1005283

Berridge CW, Waterhouse BD. 2003. The locus coeruleus-noradrenergic system: modulation of behavioral state and state-dependent cognitive processes. Brain Res Rev 42: 33-84. doi:10.1016/S0165-0173(03)00143-7

Bräunig P, Pflüger HJ. 2001. The unpaired median neurons of insects. Adv In Insect Phys 28: 185-266. doi:10.1016/S0065-2806(01)28011-4

Brembs B, Christiansen F, Pflüger HJ, Duch C. 2007. Flight initiation and maintenance deficits in flies with genetically altered biogenic amine levels. J Neurosci 27: 11122-11131. doi:10.1523/JNEUROSCI.2704-07 .2007

Burke CJ, Huetteroth W, Owald D, Perisse E, Krashes MJ, Das G, Gohl D, Silies M, Certel S, Waddell S. 2012. Layered reward signalling through octopamine and dopamine in Drosophila. Nature 492: 433-437. doi:10 $.1038 /$ nature 11614

Busch S, Selcho M, Ito K, Tanimoto H. 2009. A map of octopaminergic neurons in the Drosophila brain. J Comp Neurol 513: 643-667. doi:10 $.1002 / \mathrm{cne} .21966$

Cantarelli M, Marin B, Quintana A, Earnshaw M, Court R, Gleeson P, Dura-Bernal S, Silver RA, Idili G. 2018. Geppetto: a reusable modular open platform for exploring neuroscience data and models. Philos Trans $R$ Soc B Biol Sci 373: 20170380. doi:10.1098/rstb.2017.0380

Chang DJ, Li XC, Lee YS, Kim HK, Kim US, Cho NJ, Lo X, Weiss KR, Kandel ER, Kaang BK. 2000. Activation of a heterologously expressed octopamine receptor coupled only to adenylyl cyclase produces all the features of presynaptic facilitation in Aplysia sensory neurons. Proc Natl Acad Sci 97: 1829-1834. doi:10.1073/pnas.97.4.1829

Chapuis J, Wilson DA. 2012. Bidirectional plasticity of cortical pattern recognition and behavioral sensory acuity. Nat Neurosci 15: 155-161. doi:10.1038/nn.2966

Ciombor KJ, Ennis M, Shipley MT. 1999. Norepinephrine increases rat mitral cell excitatory responses to weak olfactory nerve input via $\alpha-1$ receptors in vitro. Neuroscience 90: 595-606. doi:10.1016/S0306-4522 (98)00437-0

Cobb M, Dannet F. 1994. Multiple genetic control of acetate-induced olfactory responses in Drosophila melanogaster larvae. Heredity 73: 444455. doi:10.1038/hdy.1994.192

Cole SH, Carney GE, McClung CA, Willard SS, Taylor BJ, Hirsh J. 2005. Two functional but noncomplementing Drosophila tyrosine decarboxylase genes: distinct roles for neural tyramine and octopamine in female fertility. J Biol Chem 280: 14948-14955. doi:10.1074/jbc.M414197200

Crittenden JR, Skoulakis EMC, Han KA, Kalderon D, Davis RL. 1998. Tripartite mushroom body architecture revealed by antigenic markers. Learn Mem 5: 38-51.

Davison IG, Ehlers MD. 2011. Neural circuit mechanisms for pattern detection and feature combination in olfactory cortex. Neuron 70: 8294. doi:10.1016/j.neuron.2011.02.047

Deady LD, Sun J. 2015. A follicle rupture assay reveals an essential role for follicular adrenergic signaling in Drosophila ovulation. PLoS Genet 11: 121. doi:10.1371/journal.pgen.1005604

de Vries SEJ, Clandinin T. 2013. Optogenetic stimulation of escape behavior in Drosophila melanogaster. J Vis Exp 2013: 50192. doi:10.3791/50192

Eichler K, Li F, Litwin-Kumar A, Park Y, Andrade I, Schneider-Mizell CM, Saumweber T, Huser A, Eschbach C, Gerber B, et al. 2017. The complete connectome of a learning and memory centre in an insect brain. Nature 548: $175-182$. doi: $10.1038 /$ nature 23455 
Escanilla O, Alperin S, Youssef M, Ennis M, Linster C. 2012. Noradrenergic but not cholinergic modulation of olfactory bulb during processing of near threshold concentration stimuli. Behav Neurosci 126: 720-728. doi:10.1037/a0030006

Estes PS, Ho GLY, Narayanan R, Ramaswami M. 2000. Synaptic localization and restricted diffusion of a Drosophila neuronal synaptobrevin: green fluorescent protein chimera in vivo. J Neurogenet 13: 233-255. doi:10 $.3109 / 01677060009084496$

Farooqui T, Robinson K, Vaessin H, Smith BH. 2003. Modulation of early olfactory processing by an octopaminergic reinforcement pathway in the honeybee. J Neurosci 23: 5370-5380. doi:10.1523/JNEUROSCI .23-12-05370.2003

Gilbert CD, Li W. 2013. Top-down influences on visual processing. Nat Rev Neurosci 14: 350-363. doi:10.1038/nrn3476

Gire DH, Restrepo D, Sejnowski TJ, Greer C, DeCarlos JA, Lopez-Mascaraque L. 2013. Temporal processing in the olfactory system: can we see a smell? Neuron 78: 416-432. doi:10.1016/j.neuron.2013.04 .033

Gordon MD, Scott K. 2009. Motor control in a Drosophila taste circuit. Neuron 61: 373-384. doi:10.1016/j.neuron.2008.12.033

Gottfried JA. 2009. Function follows form: ecological constraints on odor codes and olfactory percepts. Curr Opin Neurobiol 19: 422-429. doi:10 $.1016 /$ j.conb.2009.07.012

Greer CL, Grygoruk A, Patton DE, Ley B, Romero-Calderon R, Chang HY, Houshyar R, Bainton RJ, DiAntonio A, Krantz DE. 2005. A splice variant of the Drosophila vesicular monoamine transporter contains a conserved trafficking domain and functions in the storage of dopamine, serotonin, and octopamine. J Neurobiol 64: 239-258. doi:10.1002/neu.20146

Grossman KJ, Mallik AK, Ross J, Kay LM, Issa NP. 2008. Glomerular activation patterns and the perception of odor mixtures. Eur J Neurosci 27: 2676-2685. doi:10.1111/j.1460-9568.2008.06213.x

Hammer M. 1993. An identified neuron mediates the unconditioned stimulus in associative olfactory learning in honeybees. Nature 366: 5963. doi: $10.1038 / 366059 \mathrm{a} 0$

Hammer M, Menzel R. 1998. Multiple sites of associative odor learning as revealed by local brain microinjections of octopamine in honeybees. Learn Mem 5: 146-156.

Han KA, Millar NS, Davis RL. 1998. A novel octopamine receptor with preferential expression in Drosophila mushroom bodies. J Neurosci 18: 3650-3658. doi:10.1523/JNEUROSCI.18-10-03650.1998

Han C, Jan LY, Jan YN. 2011. Enhancer-driven membrane markers for analysis of nonautonomous mechanisms reveal neuron-glia interactions in Drosophila. Proc Natl Acad Sci 108: 9673-9678. doi:10 $.1073 /$ pnas. 1106386108

Hayar A, Heyward PM, Heinbockel T, Shipley MT, Ennis M. 2001. Direct excitation of mitral cells via activation of $\alpha 1$-noradrenergic receptors in rat olfactory bulb slices. J Neurophysiol 86: 2173-2182. doi:10.1152/jn .2001 .86 .5 .2173

Honegger KS, Campbell RAA, Turner GC. 2011. Cellular-resolution population imaging reveals robust sparse coding in the Drosophila mushroom body. I Neurosci 31: 11772-11785. doi:10.1523/JNEUROSCI $.1099-11.2011$

Jenett A, Rubin GM, Ngo TTB, Shepherd D, Murphy C, Dionne H, Pfeiffer BD, Cavallaro A, Hall D, Jeter J, et al. 2012. A GAL4-driver line resource for Drosophila neurobiology. Cell Rep 2: 991-1001. doi:10.1016/ j.celrep.2012.09.011

Jiang M, Griff ER, Ennis M, Zimmer LA, Shipley MT. 1996. Activation of locus coeruleus enhances the responses of olfactory bulb mitral cells to weak olfactory nerve input. J Neurosci 16: 6319-6329. doi:10.1523/ JNEUROSCI.16-19-06319.1996

Joerges J, Küttner A, Galizia CG, Menzel R. 1997. Representations of odours and odour mixtures visualized in the honeybee brain. Nature 387: 285288. doi: $10.1038 / 387285 \mathrm{a} 0$

Kaba H, Nakanishi S. 1995. Synaptic mechanisms of olfactory recognition memory. Rev Neurosci 6: 125-142. doi:10.1515/REVNEURO.1995.6.2 .125

Karuppudurai T, Lin TY, Ting CY, Pursley R, Melnattur K V, Diao F, White BH, Macpherson LJ, Gallio M, Pohida T, et al. 2014. A hard-wired glutamatergic circuit pools and relays UV signals to mediate spectral preference in Drosophila. Neuron 81: 603-615. doi:10.1016/j.neuron .2013 .12 .010

Kim YC, Lee HG, Lim J, Han KA. 2013. Appetitive learning requires the $\alpha 1$-like octopamine receptor oamb in the Drosophila mushroom body neurons. J Neurosci 33: 1672-1677. doi:10.1523/JNEUROSCI.3042-12 .2013

Klapoetke NC, Murata Y, Kim SS, Pulver SR, Birdsey-Benson A, Cho YK, Morimoto TK, Chuong AS, Carpenter EJ, Tian Z, et al. 2014 Independent optical excitation of distinct neural populations. Nat Methods 11: 338-346. doi:10.1038/nmeth.2836

Kreher SA, Mathew D, Kim J, Carlson JR. 2008. Translation of sensory input into behavioral output via an olfactory system. Neuron 59: 110-124. doi:10.1016/j.neuron.2008.06.010
Lee T, Luo L. 1999. Mosaic analysis with a repressible neurotechnique cell marker for studies of gene function in neuronal morphogenesis. Neuron 22: 451-461. doi:10.1016/S0896-6273(00)80701-1

Lin AC, Bygrave AM, De Calignon A, Lee T, Miesenböck G. 2014. Sparse, decorrelated odor coding in the mushroom body enhances learned odor discrimination. Nat Neurosci 17: 559-568. doi:10.1038/nn.3660

Linster C, Cleland TA. 2001. How spike synchronization among olfactory neurons can contribute to sensory discrimination. J Comput Neurosci 10: 187-193. doi:10.1023/A:1011221131212

Liu X, Davis RL. 2009. The GABAergic anterior paired lateral neuron suppresses and is suppressed by olfactory learning. Nat Neurosci 12: 5359. doi:10.1038/nn.2235

Liu C, Plaçais PY, Yamagata N, Pfeiffer BD, Aso Y, Friedrich AB, Siwanowicz I, Rubin GM, Preat T, Tanimoto H. 2012. A subset of dopamine neurons signals reward for odour memory in Drosophila. Nature 488: 512-516. doi:10.1038/nature11304

Maqueira B, Chatwin H, Evans PD. 2005. Identification and characterization of a novel family of Drosophila $\beta$-adrenergic-like octopamine G-protein coupled receptors. J Neurochem 94: 547-560. doi:10.1111/j.1471-4159 2005.03251.x

Masuda-Nakagawa LM, Tanaka NK, O'Kane CJ. 2005. Stereotypic and random patterns of connectivity in the larval mushroom body calyx of Drosophila. Proc Natl Acad Sci 102: 19027-19032. doi:10.1073/pnas .0509643102

Masuda-Nakagawa LM, Gendre N, O'Kane CJ, Stocker RF. 2009. Localized olfactory representation in mushroom bodies of Drosophila larvae. Proc Natl Acad Sci 106: 10314-10319. doi:10.1073/pnas.0900178106

Masuda-Nakagawa LM, Ito K, Awasaki T, O'Kane CJ. 2014. A single GABAergic neuron mediates feedback of odor-evoked signals in the mushroom body of larval Drosophila. Front Neural Circuits 8: 35 . doi:10 $.3389 /$ fncir.2014.00035

Matsumoto Y, Matsumoto CS, Wakuda R, Ichihara S, Mizunami M. 2015. Roles of octopamine and dopamine in appetitive and aversive memory acquisition studied in olfactory conditioning of maxillary palpi extension response in crickets. Front Behav Neurosci 9: 230. doi:10.3389/ fnbeh.2015.00230

Menzel R. 2012. The honeybee as a model for understanding the basis of cognition. Nat Rev Neurosci 13: 758-768. doi:10.1038/nrn3357

Monte P, Woodard C, Ayer R, Lilly M, Sun H, Carlson J. 1989. Characterization of the larval olfactory response in Drosophila and its genetic basis. Behav Genet 19: 267-283. doi:10.1007/BF01065910

Morita M, Susuki J, Amino H, Yoshiki F, Moizumi S, Kudo Y. 2006. Use of the exogenous Drosophila octopamine receptor gene to study Gq-coupled receptor-mediated responses in mammalian neurons. Neuroscience 137: 545-553. doi:10.1016/j.neuroscience.2005.09.012

Nagarkar-Jaiswal S, Lee PT, Campbell ME, Chen K, Anguiano-Zarate S, Gutierrez MC, Busby T, Lin WW, He Y, Schulze KL, et al. 2015. A library of MiMICs allows tagging of genes and reversible, spatial and temporal knockdown of proteins in Drosophila. Elife 4: e05338. doi:10.7554/eLife .05338

Nai Q, Dong HW, Hayar A, Linster C, Ennis M. 2009. Noradrenergic regulation of GABAergic inhibition of main olfactory bulb mitral cells varies as a function of concentration and receptor subtype. J Neurophysiol 101: 2472-2484. doi:10.1152/jn.91187.2008

Nern A, Pfeiffer BD, Rubin GM. 2015. Optimized tools for multicolor stochastic labeling reveal diverse stereotyped cell arrangements in the fly visual system. Proc Natl Acad Sci 112: E2967-E2976. doi:10.1073/pnas .1506763112

Nicolaï LJJ, Ramaekers A, Raemaekers T, Drozdzecki A, Mauss AS, Yan J, Landgraf M, Annaert W, Hassan BA. 2010. Genetically encoded dendritic marker sheds light on neuronal connectivity in Drosophila. Proc Natl Acad Sci 107: 20553-20558. doi:10.1073/pnas.1010198107

Olshausen BA, Field DJ. 2004. Sparse coding of sensory inputs. Curr Opin Neurobiol 14: 481-487. doi:10.1016/j.conb.2004.07.007

Osumi-Sutherland D, Costa M, Court R, O'Kane CJ. 2014. Virtual fly brain: using OWL to support the mapping and genetic dissection of the Drosophila brain. CEUR Workshop Proc 1265: 85-96.

Pauls D, Selcho M, Gendre N, Stocker RF, Thum AS. 2010. Drosophila larvae establish appetitive olfactory memories via mushroom body neurons of embryonic origin. J Neurosci 30: 10655-10666. doi:10.1523/JNEUROSC $.1281-10.2010$

Perez-Orive J, Mazor O, Turner GC, Cassenaer S, Wilson RI, Laurent G. 2002. Oscillations and sparsening of odor representations in the mushroom body. Science 297: 359-365. doi:10.1126/science. 1070502

Pfeiffer BD, Ngo TTB, Hibbard KL, Murphy C, Jenett A, Truman JW, Rubin GM. 2010. Refinement of tools for targeted gene expression in Drosophila. Genetics 186: 735-755. doi:10.1534/genetics.110.119917

Poo C, Isaacson JS. 2009. Odor representations in olfactory cortex: 'sparse' coding, global inhibition, and oscillations. Neuron 62: 850-861. doi:10 $.1016 /$ j.neuron.2009.05.022 
Rodrigues V, Siddiqi O. 1978. Genetic analysis of chemosensory pathway. Proc Indian Acad Sci Sect B Exp Biol 87: 147-160. doi:10.1007/ BF02837709

Roeder T. 2005. Tyramine and octopamine: ruling behavior and metabolism. Annu Rev Entomol 50: 447-477. doi:10.1146/annurev.ento .50 .071803 .130404

Roeder T, Seifert M, Kähler C, Gewecke M. 2003. Tyramine and octopamine: antagonistic modulators of behavior and metabolism. Arch Insect Biochem Physiol 54: 1-13. doi:10.1002/arch.10102

Rohwedder A, Wenz NL, Stehle B, Huser A, Yamagata N, Zlatic M, Truman JW, Tanimoto H, Saumweber T, Gerber B, et al. 2016. Four individually identified paired dopamine neurons signal reward in larval Drosophila. Curr Biol 26: 661-669. doi:10.1016/j.cub.2016.01.012

Sara SJ, Bouret S. 2012. Orienting and reorienting: the locus coeruleus mediates cognition through arousal. Neuron 76: 130-141. doi:10.1016/j .neuron.2012.09.011

Saumweber T, Rohwedder A, Schleyer M, Eichler K, Chen YC, Aso Y, Cardona A, Eschbach C, Kobler O, Voigt A, et al. 2018. Functional architecture of reward learning in mushroom body extrinsic neurons of larval Drosophila. Nat Commun 9: 1104. doi:10.1038/ s41467-018-03130-1

Scherer S, Stocker RF, Gerber B. 2003. Olfactory learning in individually assayed Drosophila larvae. Learn Mem 10: 217-225. doi:10.1101/lm .57903

Schroll C, Riemensperger T, Bucher D, Ehmer J, Völler T, Erbguth K, Gerber B, Hendel T, Nagel G, Buchner E, et al. 2006. Light-induced activation of distinct modulatory neurons triggers appetitive or aversive learning in Drosophila larvae. Curr Biol 16: 1741-1747. doi:10.1016/j cub.2006.07.023

Schröter U, Malun D, Menzel R. 2007. Innervation pattern of suboesophageal ventral unpaired median neurones in the honeybee brain. Cell Tissue Res 327: 647-667. doi:10.1007/s00441-006-0197-1

Schwaerzel M, Monastirioti M, Scholz H, Friggi-Grelin F, Birman S, Heisenberg M. 2003. Dopamine and octopamine differentiate between aversive and appetitive olfactory memories in Drosophila. J Neurosci 23: 10495-10502. doi:10.1523/JNEUROSCI.23-33-10495.2003

Selcho M, Pauls D, Han KA, Stocker RF, Thum AS. 2009. The role of dopamine in Drosophila larval classical olfactory conditioning. PLoS One 4: e5897. doi:10.1371/journal.pone.0005897

Selcho M, Pauls D, Huser A, Stocker RF, Thum AS. 2014. Characterization of the octopaminergic and tyraminergic neurons in the central brain of Drosophila larvae. J Comp Neurol 522: 3485-3500. doi:10.1002/cne .23616

Sinakevitch I, Mustard JA, Smith BH. 2011. Distribution of the octopamine receptor AmOA1 in the honey bee brain. PLoS One 6: e14536. doi:10 .1371 /journal.pone.0014536

Slater G, Levy P, Andrew Chan KL, Larsen C. 2015. A central neural pathway controlling odor tracking in Drosophila. J Neurosci 35: 1831-1848. doi:10 $.1523 /$ JNEUROSCI.2331-14.2015

Smith BH, Menzel R. 1989. The use of electromyogram recordings to quantify odourant discrimination in the honey bee, Apis mellifera. $J$ Insect Physiol 35: 369-375. doi:10.1016/0022-1910(89)90110-8

Sombati S, Hoyle G. 1984. Central nervous sensitization and dishabituation of reflex action in an insect by the neuromodulator octopamine. $J$ Neurobiol 15: 455-480. doi:10.1002/neu.480150606
Sonnhammer EL, von Heijne G, Krogh A. 1998. A hidden Markov model for predicting transmembrane helices in protein sequences. Proc AMIA Annu Fall Symp 6: 175-182.

Stettler DD, Axel R. 2009. Representations of odor in the piriform cortex. Neuron 63: 854-864. doi:10.1016/j.neuron.2009.09.005

Stevenson PA, Dyakonova V, Rillich J, Schildberger K. 2005. Octopamine and experience-dependent modulation of aggression in crickets. $J$ Neurosci 25: 1431-1441. doi:10.1523/JNEUROSCI.4258-04.2005

Stokes CCA, Isaacson JS. 2010. From dendrite to soma: dynamic routing of inhibition by complementary interneuron microcircuits in olfactory cortex. Neuron 67: 452-465. doi:10.1016/j.neuron.2010.06.029

Stopfer M, Bhagavan S, Smith BH, Laurent G. 1997. Impaired odour discrimination on desynchronization of odour-encoding neural assemblies. Nature 390: 70-74. doi:10.1038/36335

Strother JA, Wu ST, Rogers EM, Eliason JLM, Wong AM, Nern A, Reiser MB. 2018. Behavioral state modulates the on visual motion pathway of Drosophila. Proc Natl Acad Sci 115: E102-E111. doi:10.1073/pnas .1703090115

Suver MP, Mamiya A, Dickinson MH. 2012. Octopamine neurons mediate flight-induced modulation of visual processing in Drosophila. Curr Biol 22: 2294-2302. doi:10.1016/j.cub.2012.10.034

Tanaka NK, Awasaki T, Shimada T, Ito K. 2004. Integration of chemosensory pathways in the Drosophila second-order olfactory centers. Curr Biol 14: 449-457. doi:10.1016/j.cub.2004.03.006

Tao J, Bulgari D, Berkhoudt DA, Calderon MJ, Watkins SC, Velez HJF, Sabeva N, Deitcher DL, Levitan ES. 2019. Drosophila Ptp4E regulates vesicular packaging for monoamineneuropeptide co-transmission. J Cell Sci 132: jcs224568. doi:10.1242/jcs.224568

Tomchik SM, Davis RL. 2009. Dynamics of learning-related cAMP signaling and stimulus integration in the Drosophila olfactory pathway. Neuron 64: 510-521. doi:10.1016/j.neuron.2009.09.029

Treue S, Martínez Trujillo JC. 1999. Feature-based attention influences motion processing gain in macaque visual cortex. Nature 399: 575-579. doi: $10.1038 / 21176$

Turner GC, Bazhenov M, Laurent G. 2008. Olfactory representations by Drosophila mushroom body neurons. J Neurophysiol 99: 734-746. doi:10 $.1152 /$ jn.01283.2007

Venken KJT, Schulze KL, Haelterman NA, Pan H, He Y, Evans-Holm M, Carlson JW, Levis RW, Spradling AC, Hoskins RA, et al. 2011. MiMIC: a highly versatile transposon insertion resource for engineering Drosophila melanogaster genes. Nat Methods 8: 737-747. doi:10.1038/ nmeth.1662

Wilson DA, Sullivan RM. 2011. Cortical processing of odor objects. Neuron 72: 506-519. doi:10.1016/j.neuron.2011.10.027

Younossi-Hartenstein A, Salvaterra PM, Hartenstein V. 2003. Early development of the Drosophila brain: IV. Larval neuropile compartments defined by glial septa. J Comp Neurol 455: 435-450. doi:10.1002/cne.10483

Zars T, Fischer M, Schulz R, Heisenberg M. 2000. Localization of a short-term memory in Drosophila. Science 288: 672-675. doi:10.1126/science.288 .5466 .672

Received June 15, 2020; accepted in revised form October 30, 2020. 


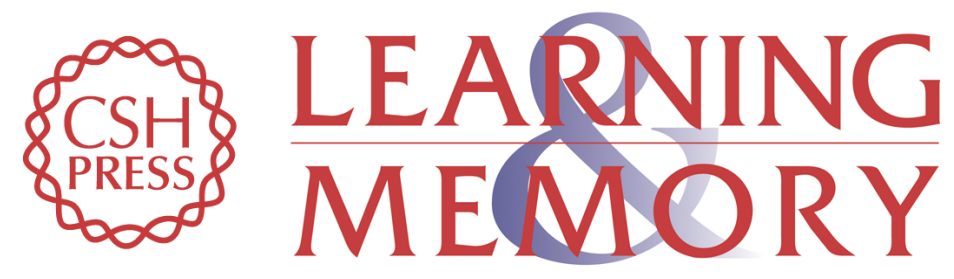

\section{Octopaminergic neurons have multiple targets in Drosophila larval mushroom body calyx and can modulate behavioral odor discrimination}

J.Y. Hilary Wong, Bo Angela Wan, Tom Bland, et al.

Learn. Mem. 2021, 28:

Access the most recent version at doi:10.1101/lm.052159.120

Supplemental http://learnmem.cshlp.org/content/suppl/2021/01/13/28.2.53.DC1

Material

References This article cites 102 articles, 25 of which can be accessed free at: http://learnmem.cshlp.org/content/28/2/53.full.html\#ref-list-1

Creative This article is distributed exclusively by Cold Spring Harbor Laboratory Press for the Commons first 12 months after the full-issue publication date (see

License http://learnmem.cshlp.org/site/misc/terms.xhtml). After 12 months, it is available under a Creative Commons License (Attribution-NonCommercial 4.0 International), as described at http://creativecommons.org/licenses/by-nc/4.0/.

Email Alerting Receive free email alerts when new articles cite this article - sign up in the box at the Service top right corner of the article or click here. 